\title{
A methodology for designing flexible multi-generation systems
}

\author{
Lythcke-Jørgensen, Christoffer Ernst; Viana Ensinas, Adriano; Münster, Marie; Haglind, Fredrik
}

\author{
Published in: \\ Energy
}

Link to article, DOI:

10.1016/j.energy.2016.01.084

Publication date:

2016

Document Version

Peer reviewed version

Link back to DTU Orbit

Citation $(A P A)$ :

Lythcke-Jørgensen, C. E., Viana Ensinas, A., Münster, M., \& Haglind, F. (2016). A methodology for designing flexible multi-generation systems. Energy, 110, 34-54. https://doi.org/10.1016/j.energy.2016.01.084

\section{General rights}

Copyright and moral rights for the publications made accessible in the public portal are retained by the authors and/or other copyright owners and it is a condition of accessing publications that users recognise and abide by the legal requirements associated with these rights.

- Users may download and print one copy of any publication from the public portal for the purpose of private study or research.

- You may not further distribute the material or use it for any profit-making activity or commercial gain

- You may freely distribute the URL identifying the publication in the public portal

If you believe that this document breaches copyright please contact us providing details, and we will remove access to the work immediately and investigate your claim. 


\section{A methodology for designing flexible}

\section{2 multi-generation systems}

3 Christoffer Lythcke-Jørgensen ${ }^{a *}$, Adriano Viana Ensinas ${ }^{b}$, Marie Münster ${ }^{c}$, Fredrik Haglind ${ }^{a}$.

$4 \quad$ a Technical University of Denmark, Mechanical Engineering

$5 \quad{ }^{b}$ École Polytechnique Fédérale de Lausanne, Industrial Process and Energy Systems Engineering

$6 \quad{ }^{c}$ Technical University of Denmark, Management Engineering

7 * Corresponding author. Email: celjo@mek.dtu.dk. Phone: +45304272 00. Nils Koppels Allé 403, 2800 Kgs.

$8 \quad$ Lyngby, Denmark.

\section{Abstract}

A flexible multi-generation system (FMG) consists of integrated and flexibly operated facilities that provide multiple links between the various layers of the energy system. FMGs may facilitate integration and balancing of fluctuating renewable energy sources in the energy system in a cost- and energy-efficient way, thereby playing an important part in smart energy systems.

The development of efficient FMGs requires systematic optimization approaches. This study presents a novel, generic methodology for designing FMGs that facilitates quick and reliable pre-feasibility analyses. The methodology is based on consideration of the following points: Selection, location and dimensioning of processes; systematic heat and mass integration; flexible operation optimization with respect to both short-term market fluctuations and long-term energy system development; global sensitivity and uncertainty analysis; biomass supply chains; variable part-load performance; and multi-objective optimization considering economic and environmental performance. 
21 Tested in a case study, the methodology is proved effective in screening the solution space for efficient

22 FMG designs, in assessing the importance of parameter uncertainties and in estimating the likely

23 performance variability for promising designs. The results of the case study emphasize the importance of

24 considering systematic process integration when developing smart energy systems.

25 Keywords: Design optimization, energy efficiency, flexible operation, multi-generation, polygeneration,

26 smart energy systems

$27 \quad$ Nomenclature

28 Latin letters

$29 A_{a}$

$30 \quad b$

$31 C_{H E N}$

$32 C_{i n v, k}$

$33 \quad C_{i n v, k 0}$

$34 \quad c_{b}$

$35 \quad c_{b 0}$

$36 c_{b, t r}$

$37 \quad c_{o p}$

$38 \quad D_{p}$

$39 d_{t r, a}$

$40 \quad \dot{e}_{f}$

$41 \quad E E$

$42 f$

$43 \quad G_{i}$

$44 \Delta H_{s, i}$
Area size

Number of parameter value levels in Morris screening

Heat exchanger network investment cost

Process investment cost

Process reference investment cost

Marginal biomass cost

Reference biomass cost

Marginal biomass logistics cost

Operating cost

Uncertainty distribution of parameter $p$

Mean transportation distance from area $a$

Thermal energy flow

Elementary effect

Model output function

CHOP group

Sum of enthalpy flows in temperature interval $s$ $\left[\mathrm{km}^{2}\right]$

$[-]$

[Euro]

[Euro]

[Euro]

[Euro]

[Euro]

[Euro]

[Euro]

[-]

$[\mathrm{km}]$

$[\mathrm{kW}]$

[-]

[kW] 
49 mean $_{i} \quad$ Estimated standard error of the mean

Operating point

Parameter

Product or service market

$57 \quad R_{t h}$

Thermal energy market

$58 \quad R_{b}$

Local biomass market

$59 \quad r_{a}$

Maximum transportation distance, area $a$

$[\mathrm{km}]$

$60 s_{\max }$

Number of temperature intervals 


\section{Greek letters}

73

$74 \quad \lambda_{k, i}$

$75 \quad v_{k, i}$

$76 \sigma_{k}$

$77 \quad \sigma_{k 0}$

$78 \sigma_{u t}$

$79 \omega_{k}$

80

$81 \quad a$

$82 \quad b$

$83 f$

$84 i$

$85 j$

$86 k$

$87 \quad l$

$88 n$

$89 \quad p$

$90 \quad r$

$91 \quad s$

920
Perturbation factor in Morris screening

Process load of process $k$ in period $i$

Operation of process $k$ in period $i$

Dimension of process $k$

Process $k$ reference dimension

Utility process dimension

Installation decision for process $k$
$[-]$

$[-]$

$[-]$

$[-]$

$[-]$

$[-]$

$[-]$

Biomass cultivation area index

Biomass flow index

Thermal and mass flow index

Period index

Operating point index

Process index

Layer index, used in the Mixed Integer-Linear Programming model

Characteristic parameter interval index

Parameter index

Market index

Temperature interval index

Reference 
$94 \quad A D \quad$ Combined anaerobic digester and biogas upgrading facility

95 BB Biomass boiler

96 CCHP Combined cooling, heating and power

97 CHOP Characteristic operating pattern

98 CHP Combined heat and power

99 DESS Distributed energy supply system

100 FMG Flexible multi-generation system

101 GB Gas boiler

102 GT Gas turbine

103 GWP100a 100-years global warming potential

104 HP Ground-based district heating heat pump

105 LCA Life cycle assessment

106 MILP Mixed integer-linear programming

107 MINLP Mixed integer-nonlinear programming

108 NPV Net present value

109 SMG Static multi-generation plant

110 SR Steam Rankine cycle 
112

113

\section{Introduction}

Flexible multi-generation systems (FMGs) are integrated, dynamic facilities that convert one or several energy resources into multiple energy services and other valuable products, e.g. electricity, heating, cooling, bio-fuels, and bio-chemicals [1]. FMGs are characterised by their ability to adjust operation in response to fluctuating demand patterns and varying price schemes. In the present work, the following definition of an FMG is introduced:

- A flexible multi-generation system (FMG) is a system of integrated facilities that provide multiple links between layers of the energy system, enabling adjustable operation in response to changes in prices and demands of the consumed and delivered services. ${ }^{1}$

The main advantages of FMGs are: The embedded possibility for optimizing operation by altering feedstock, products and services depending on demand and market price [2][3][4]; the possibility of integrating and balancing generation from intermittent renewable energy resources such as wind, solar, wave and tidal in a cost-efficient way [5][6][7], and the possibility of achieving high aggregated conversion efficiencies through process integration [8][9][10][11]. Through the conversion, conditioning and storing of multiple energy vectors, FMGs integrate the various layers of the energy system and are capable of providing supplydemand flexibility that can counteract energy system imbalances induced by e.g. intermittent renewable energy sources. In principle, FMGs can therefore be seen as efficient energy system valves that may play an important part in the development and operation of smart energy systems [12][13]. The generic FMG concept is illustrated in Figure 1.

\footnotetext{
${ }^{1}$ In specific cases, the definition of an FMG may be overlapping with the terms 'polygeneration' and 'energy hubs'. In a recent review, Adams and Ghouse [75] have defined 'polygeneration' as a thermochemical process which simultaneously generates electricity and produces at least one type of chemical or fuel without being a co- or tri-generation unit. 'Energy hubs' may refer to homes, large energy consumers, power plants or regions [76] as well as integrated facilities [4][77]. The FMG definition is introduced here in order to characterize integrated facilities that may actively contribute to the balancing of the energy system.
} 
131 By definition, FMGs may be either centralized facilities or distributed systems, as long as the various

132 facilities are integrated. The present manuscript differentiates between a plant, in which all considered

133 facilities are co-located, and a system, in which facilities are distributed on several locations. It should be 134 emphasized that FMGs may include static processes, e.g. cellulosic ethanol production [14] as well as 135 intermittent processes that are not fully dispatchable, e.g. wind turbines and solar heating, as long as the 136 combined system has a degree of operational flexibility.

137 The issues to be considered when designing FMGs comprise: The selection of processes and technologies 138 from many alternatives; geographical location, dimensioning, and integration of processes with respect to 139 thermal and mass flows; operation optimization with respect to hourly demand and price fluctuations and 140 long-term energy system development; determination of local resource availability; investment planning; 141 systematic evaluation of design uncertainties; and consideration of both economic and environmental 142 objectives. All of these issues must be considered simultaneously as they affect one another. To cope with 143 this complexity, a systematic optimization approach is needed for the design of FMGs [8].

144 One branch of multi-generation plants treated in the literature combines the generation of power and 145 production of chemicals. Gassner and Maréchal [15] presented a combined mixed integer-nonlinear 146 programming (MINLP)/mixed integer-linear programming (MILP) methodology for the synthesis of facilities 147 producing fuel from biomass through thermochemical conversion. The methodology considered the 148 selection and dimensioning of processes, systematic process integration using pinch analysis, and 149 assessment of multiple objectives including thermo-economic performance. In a second work the 150 methodology was enhanced to allow for the systematic inclusion of life cycle assessment (LCA) in the 151 design evaluation [16]. The methodology was later applied in a case study of a static multi-generation plant 152 (SMG) generating fuel and electricity from biomass [17]. The developed methodology did not consider 153 flexible operation and input parameter uncertainties.

154 Liu et al. studied SMGs generating power and methanol. In five related works, the group first presented a 155 multi-period MILP model for the design and investment planning optimization of such SMGs whilst 
considering static operating conditions over periods of 5 years [18]. The model was later upgraded to an MINLP model [19] and extended to allow for multi-objective optimization [20] and stochastic programming using a decomposition strategy [21]. The group further presented one methodology for general investment planning and one for detailed design configuration of SMGs [22]. However, neither of the presented methodologies considered short-term operation flexibility.

Chen et al. also studied the multi-generation of power and chemicals. In three consecutive works, the group first presented a deterministic superstructure-based optimization model for designing static SMGs coproducing power, naphtha, diesel, and methanol from coal and biomass [23]. The model was later enhanced to allow for flexible operation optimization with respect to price variations over seasonal peakand off-peak periods, and, based on a case study, the group concluded that FMGs may achieve higher net present values (NPVs) than static ones because of the operation flexibility, however at the cost of larger investments [24]. In a third study, the group implemented a modified decomposition algorithm based on the generalized Benders decomposition in their optimization model to reduce computational time [25], and demonstrated in two case studies that the modified methodology achieved faster calculation times than the BARON solver [26]. The group applied simple energy balances rather than detailed process integration methodologies to simulate process integration possibilities, which may have led to overestimated efficiency improvements, as also discussed by the authors [27]. Furthermore, uncertainties were not considered. Another branch of multi-generation plants are facilities based on the combined generation of cooling, heating, and power (CCHP), also known as trigeneration. Marnay et al. [28] presented a methodology for 175 minimizing the overall costs of CCHPs in commercial buildings by selecting and dimensioning technologies 176 and optimizing operation based on diurnal load profiles. Rubio-Maya et al. [29][30] presented a heuristic, 177 two-level approach for designing local FMGs generating power, heat, cooling and fresh water. Selection of 178 technologies and a preliminary process dimensioning were handled in a first step based on monthly179 averaged requirements, while a second step dealt with the final dimensioning of components, including 180 thermal energy storage, based on monthly mean-day demands. Piacentino et al. [31] presented a 
deterministic MILP-based tool for optimizing trigeneration-based micro-grids with thermal storages with respect to NPV. Capuder and Mancarella [32][33] presented a framework for the techno-economic and environmental comparison of seven distributed FMG options for co-generating heat and power. The framework considered half-hour time steps on typical seasonal days, thermal energy storage, and ramp rate constraints between successive time periods. The group found that increased operation flexibility resulted in significant savings in investment and operating costs as well as in a reduced environmental impact when compared to the reference case of a district heating boiler. Recently, Capuder et al. [34] extended their work to consider the economic value of operational flexibility and investment flexibility under long-term operational uncertainty and found that consideration of investment flexibility both reduced expected costs and economic risks associated with investments in distributed FMGs co-generating heat and power.

With regard to distributed energy supply systems (DESS), Voll et al. [35] developed an approach for the superstructure-free synthesis and optimization of DESS using an evolutionary algorithm and applied the method on a numerical example of a DESS with time-varying heating and cooling loads. Following this, Voll et al. [36] presented a framework for automated superstructure generation and optimization of DESS using an MILP model. The group further developed a method for reducing non-linear DESS optimization problems into MILP models using a multivariate piecewise-affine surrogate modelling approach [37], and a method for exploring the near-optimal solution space when optimizing DESS [38]. In a recent study, the group presented a hybrid approach for optimizing the synthesis of renewable electricity systems by combining heuristic-based pre-selection of candidate technologies with the previously developed automated superstructure generation and optimization of DESS [39]. Zhou et al. [40] presented a two-stage stochastic programming model for designing DESS which further allowed for the consideration of uncertainties in the optimization. Finally, Leung Pah Han et al. [41] presented an iterative method combining MILP/MINLP for designing local production systems that integrate food, water, and energy systems based on annual demands, with the aim of minimizing the cumulative exergy destruction. 
Concerning urban multi-generation plants, Lythcke-Jørgensen and Haglind [42] studied the design and operation optimization of an FMG generating power and heat and producing cellulosic ethanol. The study found that short-term operating patterns may be critical for the overall economy of FMGs. Maréchal et al. [43] presented a multi-period, multi-objective MINLP/MILP approach for deterministic design optimization that comprised technology selection and dimensioning, process integration, facility location selection, and network layout. By considering monthly static operating patterns, Fazlollahi and Maréchal [44] used parts of this methodology for designing FMGs that provide energy services for district energy systems. In three parallel works, the group extended their work by incorporating the following methodology: A method for approximating energy system conditions by a number of typical periods with hourly and aggregated multihour time steps [45]; a model of daily thermal storages [46]; and a model of distribution networks [47]. Shortcomings of the combined methodology are the facts that only cyclic short-term operating patterns may be considered using the typical periods approach, and that input parameter uncertainties are not considered.

This study presents a novel, systematic methodology for designing FMGs. It applies node-based superstructure representation and is based on a genetic algorithm and multi-period MILP approach [48]. The purpose of the methodology is to conduct quick and reliable pre-feasibility analyses of FMGs for assessing which of the facility designs that would be efficient in a given energy system context, rather than estimating the optimal performance of pre-defined facility designs. The novelty of the methodology lies in the fact that it simultaneously considers the following: Selection, location, and dimensioning of processes from many alternatives; systematic heat and mass integration using pinch analysis; flexible operation optimization with respect to both short-term market fluctuations and long-term energy system development through the application of the Characteristic Operating Pattern (CHOP) method [49]; investment planning; global sensitivity and uncertainty analysis; consideration of local resource availability, biomass supply chains, and market sizes; variable part-load performance; and multi-objective optimization 
considering NPV and 100-years global warming potential (GWP100a). To the author's best knowledge, no previous methodology has considered all of these aspects in an integrated, systematic manner.

The paper is structured as follows: After the introduction, which also features a short literature review on methodologies for designing multi-generation systems, the developed design methodology is presented in Section 2. In Section 3, the methodology is applied in a case study of a conceptual FMG co-generating power and heat and producing cellulosic ethanol, synthetic natural gas, and fertilizer from natural gas, domestic and industrial waste, straw, and manure. Section 4 contains a discussion on advantages, drawbacks, and development possibilities for the design methodology. A conclusion on the study is given in Section 5 .

\section{Design methodology}

The design methodology developed in the present study is a tool for optimizing the design and operation of FMGs by coupling process models with energy system information, as illustrated in Figure 2 . The structure of the design methodology is presented in Figure 3, which illustrates how the optimization problem has been decomposed into several parts. The design methodology is introduced in this section, which is structured according to the five overarching steps of the methodology.

\subsection{Input data}

In general, four types of input data are required for running the design methodology: Process and equipment models, energy system data, local resource data, and life cycle inventory data. If sensitivity and uncertainty analyses are to be performed on selected designs, uncertainty distributions for input data $D_{p}$ must be defined for all the considered uncertain input parameters $p$.

\section{Process and equipment models}

The first input to the design methodology is models of the processes and equipment to be considered for the FMG. The models can be detailed thermodynamic and chemical models as well as simpler black box 
models, as long as they provide the information required for developing surrogate models, as discussed in

Section 2.2.

\section{Energy system data}

The second input to the design methodology is data on the surrounding energy system that the FMG is to operate within. Depending on the processes considered, energy system data may include parameters such as power price, demands for district energy, fossil fuel prices, subsidy schemes etc. All information must be provided for short time intervals, a few hours or less, in order to include details on short-term fluctuations in prices and demands that the FMG may respond to. The data must be provided for the entire lifetime of 261 the FMG.

Local resource data

263 Local resource data describe the availability, costs, and logistics of local resources considered for processing 264 in the FMG, e.g. biomass, manure, domestic, and industrial waste etc. This information can be essential for 265 the economic viability of FMGs, as transportation and storage costs for processing locally distributed resources may induce a diseconomy-of-scale trend that can exceed the economy-of-scale benefits for larger processing equipment, as also discussed by Jack [50].

\section{Life cycle inventory data}

269 The environmental impact parameter considered in the design methodology is the 100-years global 270 warming potential (GWP100a). GWP100a is an indicator of the global warming impact over a 100-year 271 period from materials mining, production of equipment, installation, operation and maintenance, and 272 decommissioning of a facility, measured in equivalent tons of $\mathrm{CO}_{2}$ emissions. In order to consider the 273 minimization of GWP100a when designing FMGs, life cycle inventory data must be provided on all 274 considered process equipment, consumed resources, displaced production and consumption etc. 


\subsubsection{CHOP-reduction of external operating conditions}

In order to reduce computation time, external operating conditions are reduced using the Characteristic Operating Pattern (CHOP) method introduced by Lythcke-Jørgensen et al. [49]. The CHOP method is a visually-based aggregation method for clustering data on external operating conditions. Aggregation is conducted based on important parameter values rather than time of occurrence, thereby preserving important information on short-term relations between the relevant operating parameters. The $\mathrm{CHOP}$ method is briefly introduced below. Details on contents, validation, and application of the CHOP method have been given previously [49].

The CHOP method assumes quasi-static operation and is applicable on datasets in the form of operating points $O_{j}$, with each point being characterised by a year of occurrence after operation initiation $Y_{j}$, a duration $t_{j}$, and a number of operating condition parameters $\boldsymbol{p}_{\boldsymbol{j}}$.

$$
O_{j}=\left\{Y_{j}, t_{j}, \boldsymbol{p}_{j}\right\}
$$

A principal sketch of the data aggregation principle applied in the CHOP method is presented in Figure 4.

The CHOP method consists of the three principal steps, which are described below:

\section{1: Entity selection}

In the first step of the CHOP-method, the user has to identify the relevant volatile operating parameters $\boldsymbol{p}$ for the FMG of interest. The parameters selected are to be seen as boundary conditions for the operation of the FMG, and parameter values are therefore assumed to be unaffected by FMG operation. This assumption needs to be validated, perhaps à posteriori, when applying the design methodology. Relevant operating parameters could be power price, fossil fuel prices, and $\mathrm{CO}_{2}$ tax schemes, depending on the processes considered for the FMG and the energy system of interest. If price functions can be established for some boundary conditions as a function of FMG operation, the function constants can be captured in the vector $\boldsymbol{p}_{\boldsymbol{i}}$ as well. 


\section{2: Clustering criteria}

300

301

302 Having identified the relevant parameters $\boldsymbol{p}$, the second step is to define the criteria for clustering operating points. This is done by splitting the value range of each relevant parameter $p$ into a number of characteristic intervals, $n_{p}$, using a graphic-based two-step approach based on the cumulative parameter curve. The process is illustrated in Figure 5 with power price chosen as parameter.

a) Important values: Some parameter values may be of special interest, making it relevant to introduce a break at these points. For instance, for the power price example, it may be relevant to introduce a break at a power price of 0.00 Euro/MWh to make sure that negative prices are grouped together. Also, if an operating decision, e.g. turning on a piece of equipment, is dependent on a given power price, an interval break should be introduced at this price as well.

b) Even division: If the already set break-points are far from each other in terms of both parameter value and duration, it is suggested that additional interval breaks are introduced to minimize the span. The break-points should be located such that the parameter value range is constant for each of the intervals.

\section{3: Cluster procedure}

Having defined the clustering criteria, the final step is to cluster the data in order to establish the final CHOP-groups $G_{i}$ to replace the initial dataset of operating points $O_{j}$. Each $G_{i}$ is characterised by a unique combination of characteristic parameter intervals, causing the maximum number of $\mathrm{CHOP}$-groups to be:

$$
N_{C H O P, \max }=\prod_{p} n_{p}
$$

All initial operating points $O_{j}$ are sorted into the CHOP groups $G_{i}$ based on parameter values. Any $G_{i}$ with no $O_{j}$ belonging to it is discarded. Each included $G_{i}$ becomes an operating point in the final CHOP-reduced dataset characterised by a duration $t_{i}$ (the sum of durations of the aggregated data points), a present value factor $t_{P V, i}$, and a number of operating condition parameters $\boldsymbol{p}_{\boldsymbol{i}}$, which are the weighted average parameter values of the aggregated data points.

$$
G_{i}=\left\{t_{i}, t_{P V, i}, \boldsymbol{p}_{i}\right\}
$$




$$
t_{i}=\sum_{o_{j} \in G_{i}} t_{j}
$$

$$
t_{P V, i}=\sum_{o_{j} \in G_{i}} \frac{t_{j}}{(1+i)^{Y_{j}}}
$$

with $i$ being the annual discount rate.

If investment planning is not taken into account, a single CHOP-reduced dataset can be used for representing operating conditions over the lifetime of the FMG to be designed. In case investment planning is to be considered, one has to define a number intervals at the end of which novel investments are allowed, e.g. every $5^{\text {th }}$ year, as suggested by Liu et al. [18]. If so, individual CHOP dataset must be developed for each investment interval, increasing the overall number of periods significantly in the final optimization model.

\subsubsection{Surrogate modelling}

In the design methodology, process and market models are reduced to step-wise linearized surrogate models in order to fit them into the optimization model developed. A generic illustration of a surrogate process model $K\left(\sigma_{k}, \lambda_{k, i}\right)$, defined by a dimension $\sigma_{k}$ and load $\lambda_{k, i}$, is presented in Figure 6 .

Each surrogate process model $K\left(\sigma_{k}, \lambda_{k, i}\right)$ is characterized by: A number of mass flows into the process $\dot{\boldsymbol{m}}_{\boldsymbol{i n , \boldsymbol { k }}}\left(\sigma_{k}, \lambda_{k, i}\right)$, and mass flows out of the process $\dot{\boldsymbol{m}}_{\boldsymbol{o u t}, \boldsymbol{k}}\left(\sigma_{k}, \lambda_{k, i}\right)$; a number of internal thermal energy flows $\dot{\boldsymbol{e}}_{\text {internal, } \boldsymbol{k}}\left(\sigma_{k}, \lambda_{k, i}\right)$, thermal energy flows into the process $\dot{\boldsymbol{e}}_{\boldsymbol{i n}, \boldsymbol{k}}\left(\sigma_{k}, \lambda_{k, i}\right)$, and thermal energy flows out of the process $\dot{\boldsymbol{e}}_{\text {out }, \boldsymbol{k}}\left(\sigma_{k}, \lambda_{k, i}\right)$; plus investment costs $C_{i n v, k}(\sigma)$ and operating costs $C_{o p, k}(\sigma, \lambda)$. 342 Furthermore, dimensional and operational constraints may be associated with each $K\left(\sigma_{k}, \lambda_{k, i}\right)$. Each mass 343 flow function $\dot{m}_{f, i}\left(\sigma_{k}, \lambda_{k, i}\right)$ and operating cost function $c_{o p, k}\left(\sigma_{k}, \lambda_{k, i}\right)$ must be a linear or step-wise linear 344 function of the load $\lambda_{k, i}$ as defined in equations (7) and (8). Each thermal energy flow function $\dot{e}_{f, i}\left(\sigma_{k}, \lambda_{k, i}\right)$ 345 is characterized by an inlet temperature $T_{i n, f}$, an outlet temperature $T_{\text {out, }}$, and a heat flow capacity 
$C \dot{P}_{f, l}\left(\sigma_{k}, \lambda_{k, i}\right)$ as defined in equation (9), with the latter being a linear or step-wise linear function of the load $\lambda_{k, i}$ as defined in equation (10).

$$
\begin{gathered}
\dot{m}_{f, i}\left(\sigma_{k}, \lambda_{k, i}\right)=f_{\text {linear }}\left(\sigma_{k}, \lambda_{k, i}\right)=\left\{\begin{array}{c}
\sigma_{k}\left(a_{1} \lambda_{k, i}+b_{1}\right), \lambda_{k, i} \epsilon I_{1} \\
\sigma_{k}\left(a_{2} \lambda_{k, i}+b_{2}\right), \lambda_{k, i} \in I_{2} \\
\ldots
\end{array}\right. \\
c_{\text {op }, k}\left(\sigma_{k}, \lambda_{k, i}\right)=f_{\text {linear }}\left(\sigma_{k}, \lambda_{k, i}\right)=\left\{\begin{array}{c}
\sigma_{k}\left(c_{1} \lambda_{k, i}+d_{1}\right), \lambda_{k, i} \in I_{1} \\
\sigma_{k}\left(c_{2} \lambda_{k, i}+d_{2}\right), \lambda_{k, i} \in I_{2} \\
\ldots
\end{array}\right.
\end{gathered}
$$

In the equations, $I_{1}, I_{2}, \ldots$ are the load intervals for which the step-wise linear functions apply, while $\{a, b, c, d, g, h\}$ represent linear function constants. Note that power flows are modelled as mass flows as they do not require quality differentiation in process integration methods.

To represent possible economy of scale effects, power laws [51] are used to calculate investment costs $C_{i n v, k}\left(\sigma_{k}\right)$ of the surrogate process models as a function of the dimension $\sigma_{k}$ and a scaling constant $M_{f, k}$ :

$$
C_{i n v, k}\left(\sigma_{k}\right)=C_{i n v, k 0}\left(\frac{\sigma_{k}}{\sigma_{k 0}}\right)^{\mathrm{M}_{\mathrm{f}, \mathrm{k}}}
$$

with $C_{i n v, k 0}$ being the reference investment cost and $\sigma_{k 0}$ the reference dimension of the process $K$.

Multiple process models may be merged into combined surrogate models if they are synchronized, i.e. their dimensions are aligned and they share the same load pattern at all times. Processes with non-synchronised dimensions and load patterns must be assigned individual surrogate models.

A generic illustration of surrogate models for product or service markets, $R\left(\boldsymbol{\lambda}_{\boldsymbol{i}}\right)$, thermal energy markets $R_{t h}\left(\lambda_{i}\right)$, and local biomass markets $R_{b}\left(q_{b, a n}\right)$, which are functions of the FMG load vectors $\lambda_{i}$, are presented in Figure 7.

Each surrogate product market model $R$ is characterized by: Mass flows of bought and sold products $\dot{m}_{\text {bought }}(\lambda), \dot{m}_{\text {sold }}(\lambda)$; product price as a function of FMG operation $c(\lambda)$; and production and demand 
constraints. Each surrogate thermal energy market model $R_{t h}$ is characterised by: Forward and return thermal energy flows $\dot{e}_{\text {forward }}(\lambda), \dot{e}_{\text {return }}(\lambda)$; thermal energy service price as a function of FMG operation $c_{t h}(\lambda)$; temperatures of the thermal flows $T_{\text {forward }}, T_{\text {return }}$; and generation and demand constraints. Each surrogate local biomass market model is characterized by a mass flow of biomass $\dot{m}_{b}\left(q_{b, a n}\right)$ and a vector of marginal biomass costs $\boldsymbol{c}_{\boldsymbol{b}}\left(q_{b, a n}\right)$ as functions of the annual biomass demand $q_{b, a n}$, as described in more detail in Section 2.2.3.

\subsubsection{Biomass supply chain modelling}

If local biomass resources are to be consumed, a biomass supply chain model must be established to relate the marginal biomass unit cost to the biomass feedstock consumption. As discussed by e.g. Jack [50] and Boldrin et al. [52], transportation costs may be central of the economic analysis of local biomass resources. In the present methodology, a generic biomass supply chain model is integrated analogous to the one developed for sugar beet by Boldrin et al. [52].

In the model, the biomass unit cost $c_{b}\left(q_{b, a n}\right)$ as a function of the annual biomass quantity demanded $q_{b, a n}$ is assumed to consist of two components, namely a reference cost $c_{b 0}$ and a cost for transportation, $c_{b, t r}\left(q_{b, a n}\right)$. The reference cost is a fixed cost representing the price paid to the local farmers for the biomass, while the transportation cost represents the variable costs of logistics for delivering biomass to the FMG.

$$
c_{b}\left(q_{b, a n}\right)=c_{b 0}+c_{b, t r}\left(q_{b, a n}\right)
$$

In order to calculate $c_{b, t r}\left(q_{b, a n}\right)$, the land around the FMG is assumed divided as illustrated in Figure 8 .

It is assumed that the transportation cost for all biomass cultivated in an area $A_{h}$ is constant and equal to the cost of transporting the biomass the mean transportation distance $d_{t r, h}$, which is calculated as

$$
d_{t r, a}=r_{a-1}+\left(\frac{r_{a}-r_{a-1}}{\sqrt{2}}\right)
$$

The marginal biomass unit cost $c_{b}\left(q_{a n}\right)$ is then calculated as 


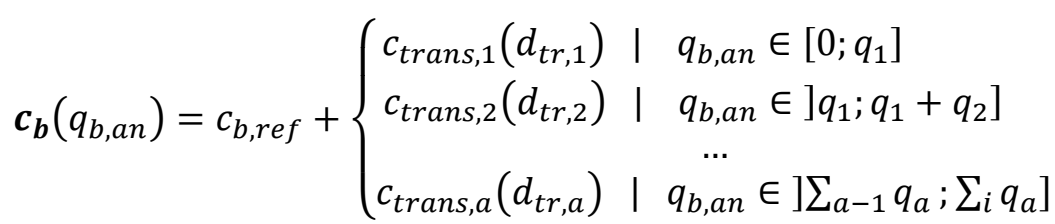

The annual biomass cultivation $q_{a}$ in each area $A_{a}$ is calculated from the input data on local resources.

The identified marginal biomass costs are included in the CHOP-reduced dataset for external operating conditions. This implies that any variation in the marginal biomass costs over the seasons or years can be taken into account in the optimization model. If several local biomass feedstocks are considered for processing, multiple BCM models can be defined in the design methodology.

\subsection{Optimization phase}

The optimization phase of the design methodology is based on a genetic algorithm and a multi-period mixed integer-linear programming (MILP) model from the OSMOSE software [48], which is developed at École Polytechnique Fédérale de Lausanne, Industrial Process and Energy Systems Engineering lab. In short, the optimization phase consists of three steps: 1. A genetic algorithm, used for selecting, locating, and dimensioning processes to be included in an FMG, and deciding upon possible investment plans; 2 . a multiperiod MILP model for optimizing process integration and operation of the given processes over the lifetime of the facility, and 3. a post calculation step for calculating the overarching objective function values of each optimized design. The calculated objective function values are provided as feedback to the genetic algorithm. The three steps are described in detail below.

\subsubsection{Genetic algorithm}

A genetic algorithm developed at EPFL [48] is used for selecting, locating and dimensioning processes to be included in the FMG, and for determining the strategy if investment planning is considered. The genetic algorithm is preferred as the master optimization algorithm as it can be used for solving linear as well as non-linear models and is capable of conducting multi-objective optimization [53]. 
411 In short, a genetic algorithm is a heuristic optimization algorithm that imitates the process of natural 412 selection for solving an optimization problem. The variables of the optimization problem are seen as 'genes', 413 while the objective function or functions describe the 'Darwinian fitness' of a solution. To start with, a 414 population of a defined number of solutions with randomly assigned genes is generated, and the fitness of 415 each solution is assessed. Next, a second population is 'bred' from a selected number of well-performing 416 'parent' solutions from the first population. The new solutions inherit genes from the parent solutions as 417 defined by the genetic operator crossover, while some of the inherited genes may be altered by the genetic operator called mutation. The genetic algorithm then iterates over a defined number of generations in search for optimal combinations of genes.

When running the genetic algorithm in OSMOSE, one defines the population size and number of generations, while the algorithm has pre-defined settings for selection, mutation, and crossover [48]. For general information on genetic algorithms, consult e.g. [54].

The objectives of the genetic algorithm are to minimize the negative net present value $\operatorname{NPV}(\boldsymbol{\omega}, \boldsymbol{\sigma}, \boldsymbol{y})$ and the global warming potential $\operatorname{GWP} 100 a(\boldsymbol{\omega}, \boldsymbol{\sigma}, \boldsymbol{y})$. Variables considered are $\omega_{k}$, the decision of whether or not a process or piece of equipment $k$ should be installed at a given location; $\sigma_{k}$, the dimension of $k$; and $y_{k}$, the installation delay of $k$ in years. The optimization problem to be solved by the genetic algorithm in the design methodology can be written in condensed form as

$$
\left\{\begin{array}{c}
\min _{\boldsymbol{\omega}, \boldsymbol{\sigma}, \boldsymbol{I P}}\left\{\begin{array}{c}
-N P V(\boldsymbol{\omega}, \boldsymbol{\sigma}, \boldsymbol{y}) \\
G W P 100 a(\boldsymbol{\omega}, \boldsymbol{\sigma}, \boldsymbol{y})
\end{array}\right. \\
\text { with variables } \\
\omega_{k} \in\{0,1\} \\
\sigma_{k} \in\left[\begin{array}{c}
\left.\sigma_{k, \min }, \sigma_{k, \text { max }}\right] \\
y_{k}
\end{array}\right.
\end{array}\right.
$$

429 Infrastructure for connecting facility locations is dimensioned by the genetic algorithm as well. The 430 methodology is therefore not advantageous for systems with a large number of location options. Back-up 431 utility processes are not dimensioned by the genetic algorithm, but by the MILP model based on required maximum capacities over the expected operating pattern. 


\subsubsection{Mixed integer-linear programming model}

434 Given the selection and location $\boldsymbol{\omega}$, the dimension $\boldsymbol{\sigma}$, and the time of instalment $\boldsymbol{y}$ for all processes $k$, 435 process integration and operation optimization over the lifetime of the FMG can be conducted. In order to 436 reduce computation time and to guarantee that global optimality is reached for the operation optimization, 437 a multi-period mixed integer-linear programming (MILP) model [48] is established to minimize operation $438 \operatorname{costs} c_{o p, i}\left(\boldsymbol{v}_{\boldsymbol{i}}, \boldsymbol{\lambda}_{\boldsymbol{i}}\right)$ of the given FMG layout in each CHOP group $i$, which in total represents operation 439 optimization over the lifetime of the facility. The variables are: $v_{k, i}$, the decision on whether a process $k$ is 440 running or shut down in period $i$; and $\lambda_{k, i}$, the load of the process if it is running.

441 The MILP model is constructed so that each type of mass flow in the system has its own layer $l$. Mass 442 balance applies for each layer over each period $i$ and is included as a constraint in the MILP model.

$$
\sum \dot{m}_{f, l, i}=0
$$

Special layers are constructed for thermal energy flows, for which pinch analysis [55] is applied to optimize heat integration. As heat integration over geographical distances may not be feasible, a thermal energy layer must be defined for each area within which heat integration is feasible. If all facilities considered in an FMG are co-located, it may be sufficient to define a single thermal energy layer. assumed to have step-wise constant heat capacity flow rates $\dot{\boldsymbol{C}}\left(\boldsymbol{\sigma}, \lambda_{i}\right)$ over their temperature ranges. Assuming a pinch temperature difference of $10 \mathrm{~K}$, the temperatures of hot streams are shifted $5 \mathrm{~K}$ up and the temperatures of cold streams are shifted $5 \mathrm{~K}$ down. For each thermal layer in the FMG model, enthalpy balances $\Delta H$ are calculated for each temperature interval $s$ :

$$
\Delta H_{s, i}=\left(T_{s}-T_{s-1}\right) \sum_{s} \dot{C} P_{s}\left(\boldsymbol{\sigma}, \lambda_{i}\right)
$$

454 To satisfy the first law of thermodynamics, the sum of all temperature interval enthalpy flows in each thermal energy layer must be zero. Furthermore, the sum of enthalpy flows from the first temperature interval to any of the other temperature interval in each thermal energy layer must never be below zero to make sure that the $2^{\text {nd }}$ law of thermodynamics is satisfied: 
460 The optimization problem to be solved by the MILP model in the design methodology can be written in 461 condensed form as

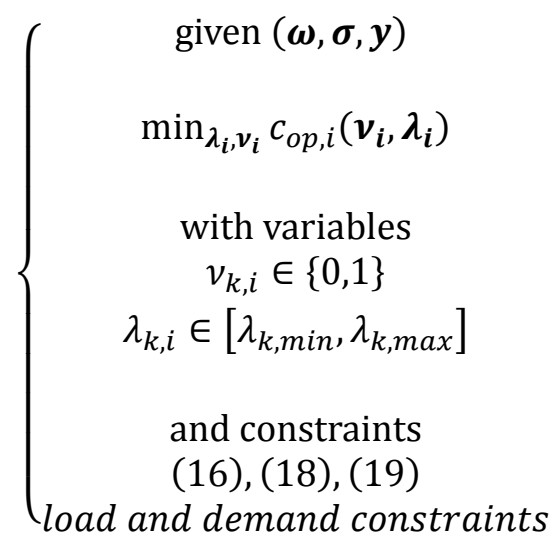

463 Once the MILP model has been solved, the global warming impact of the optimized operation $z_{o p, i}\left(\boldsymbol{v}_{\boldsymbol{i}}, \boldsymbol{\lambda}_{\boldsymbol{i}}\right)$ 464 is calculated for each period $i$.

465 In OSMOSE [48], the required investment in heat exchangers $C_{H E N, i}$ is estimated as a part of the pinch 466 analysis for each operating mode $i$ using a method from [56]. For more information, consult Bolliger [48].

467 In the MILP model, no constraint is put on the dimensions of utility services $\sigma_{u t}$ in order to make sure that 468 constraints (17) and (18) are satisfied at all operating points. Once the MILP model has been solved, $\sigma_{u t}$ is 469 identified as the largest required utility service demand experienced over the lifetime of the system, and 470 the investment cost is calculated using the power law function given in equation (11).

\subsubsection{Post computation}

Once the MILP operation optimization has been conducted, a post-calculation step is used for evaluating

473 the overall performance of the optimized FMG with respect to NPV and GWP100a.

474 First, the heat exchanger network investment cost, $C_{H E N}$, is defined as the largest estimated heat 475 exchanger investment cost as identified by OSMOSE [48]:

$$
C_{H E N}=\max _{i} C_{H E N, i}
$$

The NPV, $C_{0}$, of the design is calculated as 
479 with $y_{l t}$ being the facility lifetime and $i$ the annual discount rate.

480 The global warming potential $Z_{0}$ of the design is calculated as

$$
Z_{0}=z_{i n v, H E N}+\sum_{k} z_{i n v, k}\left(\sigma_{k}\right)+\sum_{i} z_{o p, i}\left(\boldsymbol{v}_{\boldsymbol{i}}, \lambda_{\boldsymbol{i}}\right) \cdot t_{i}
$$

Here, $z_{\text {inv,HEN }}$ is the global warming potential related to the production, installation, and scraping of the heat exchanger network, $z_{i n v, k}\left(\sigma_{k}\right)$ is the global warming potential related to the production, installation, and scraping of the process $K\left(\sigma_{k}\right)$, and $z_{o p, i}\left(\boldsymbol{v}_{\boldsymbol{i}}, \boldsymbol{\lambda}_{\boldsymbol{i}}\right) \cdot t_{i}$ is the overall global warming potential of the FMG operation in period $i$.

The calculated NPV and GWP100a are provided as feedback to the genetic algorithm. All data on optimized designs are stored in a database for later evaluation.

\subsection{Evaluation phase}

\subsubsection{Pareto assembly}

Following the optimization phase, a Pareto frontier is assembled for optimized design solutions with respect to the two objectives, NPV and GWP100a. The Pareto frontier illustrates the border between the feasible solution space and the infeasible solution space of the optimization problem. Designs placed on the

Pareto frontier are called efficient designs, as they represent the optimal pay-off between the two objectives of the optimization problem. An example of a Pareto frontier is developed as a part of the case study in Section 3 and can be seen in Figure 11.

\subsubsection{Sensitivity analysis and uncertainty analysis}

497 Design optimization of FMGs involves many sources of uncertainty, e.g. technology learning curves, energy 498 system development, policy schemes, estimated investment, operating costs etc. It is therefore important 499 to assess variations in the performance of optimized designs as functions of input data uncertainty. In the present design methodology, uncertainties with respect to external operating conditions (energy systems) 
are considered by solving the developed optimization problem for various scenarios, while uncertainties of economic and environmental parameters are considered for a number of selected designs in each scenario using the following three-step procedure for assessing output uncertainty:

1. Selection of a number of interesting designs.

2. Morris screening [57] is applied on each selected design for assessing the relative impact on performance variability from input parameter uncertainty.

3. Monte Carlo simulation is applied for quantifying performance variability of each selected design.

Uncertainties regarding topological parameters, such as equipment failure or forced outages, are not considered in the design methodology.

Morris screening: Extended Morris screening [57][58] is a global sensitivity analysis method that is applied for assessing how the various input data uncertainties affect variations in model outputs. The method relies on estimation of elementary effect $E E$ on each model output from each input parameter $p$. The main advantage of Morris screening is its low computational cost when compared to other global sensitivity analysis methods. The method uses a special sampling technique, Morris sampling, and it has two degrees of freedom to be specified by the user: $b$, the number of value levels that an uncertain input parameter can take within its range; and $w$, the number of elementary effects to be calculated for each input in order to identify the elementary effect distributions $\boldsymbol{D}_{\boldsymbol{E} \boldsymbol{E}, p_{y}}$ for each parameter $p_{y}$ on each output function $f$.

The elementary effect vector $\boldsymbol{E} \boldsymbol{E}_{p_{y}}$ for a parameter $p_{y}$ is calculated as:

$$
\boldsymbol{E} \boldsymbol{E}_{p_{y}}=\frac{\boldsymbol{f}\left(p_{1}, p_{2}, \ldots, p_{y}+\Delta, \ldots, p_{M}\right)}{\Delta}
$$

Here, $\boldsymbol{f}(p)$ are model output functions, and $M$ is the total number of uncertain model parameters considered. $\Delta$, a perturbation factor for the input parameters, is optimal when calculated as:

$$
\Delta=\frac{p}{2(p-1)}
$$

Once all $E E_{i j}$ have been calculated for $w$ random samples of input parameters, sigma-scaling [58] of $E E_{p_{y}}$ is applied so that the impacts of input parameters on various outputs can be compared: 


$$
S E E_{p_{y}, f}=E E_{i j} \frac{(\text { standard deviation })_{p_{y}}}{(\text { standard deviation })_{f}}
$$

Here, (standard deviation) $)_{y}$ is the standard deviation of the input parameter $p_{y}$, while

527 (standard deviation) $f$ is the standard deviation of the output $f$ from simulation results.

Based on the simulation results, the means and standard deviations of all sigma-scaled elementary effects

$\boldsymbol{S} \boldsymbol{E} \boldsymbol{E}_{p_{y}}$ are calculated and assembled in scatter plots. In each plot, two lines corresponding to the positive and negative double estimated standard error of the mean, mean $_{i}$, are drawn:

$$
\text { mean }_{i}= \pm 2 \cdot \frac{\text { standard deviation }_{i}}{\sqrt{w}}
$$

As described by Sin et al. [58], these lines may be used for dividing uncertain input parameters into significant or negligible with respect to model output variation. If the elementary effect of a parameter falls within the two lines, its impact can be interpreted as negligible on the model output variation.

An example of the application of Morris screening and interpretation of its results is given in the case study in Section 3.

Monte Carlo simulation: Following the Morris screening, the Monte Carlo simulation procedure presented by $\operatorname{Sin}$ et al. [58] is applied for quantifying the overall model output variation with respect to each of the two performance objectives. The Monte Carlo simulation is a technique for investigating output variability through uncertainty sampling and probability statistics. It has been chosen for the design methodology as it may provide uncertainty results without necessitating modifications or manipulations of the original models and because it facilitates identification of nonlinearities, thresholds, and discontinuities [59]. The procedure applied in the design methodology involves three steps:

1. Specifying input uncertainty: In general, the Monte Carlo simulations may consider uncertainty distributions $D$ for all input data. However, in order to reduce the number of parameter distributions to sample from, the parameters identified to have insignificant impact on model output variability in the Morris screening are not considered in the input uncertainty for the Monte Carlo simulations. 
2. Sampling from input uncertainty: In order to obtain dense stratification over the range of each sampled variable without having to define the stratification manually, the Latin Hypercube Sampling method [60] is applied for sampling from input uncertainty.

3. Evaluating the model for sampled input uncertainty: The optimization model is run for all sampled datasets. The Monte Carlo results provide a cumulative distribution function of the output functions which may be evaluated using basic statistics.

\subsection{Outputs}

The design methodology yields two overall outputs:

1. An assembled Pareto curve and a database of feasible designs that have been optimized with respect to NPV and GWP100a.

2. For selected designs:

a. The sigma-scaled elementary effect of each input parameter $p$ on each model output.

b. A quantification of model output variation as a function of input uncertainty.

To demonstrate the use of the design methodology, it is applied in a case study in Section 3.

\section{Case study: Conceptual FMG}

In this section, the developed design methodology is applied in a simple case study which treats the retrofit of an existing combined cycle combined heat and power (CHP) plant. With the aim of strengthening the integration between layers of the energy system, a number of routes for converting local biomass into power, heating, fuels, and other products are considered for integration in the CHP plant, and the impact of such integration on the overall economic and environmental performance of the plant is then assessed. The retrofit options considered include the possible installation of: A straw-based cellulosic ethanol production facility based on IBUS technology [61]; a biomethane facility, which includes an anaerobic digester producing biogas from manure, industrial waste, and ethanol production molasses, with an integrated 
biogas upgrading facility; a biomass boiler and a natural gas boiler for utility heat; and a ground-based compression heat pump for district heating generation. A superstructure of possible retrofit options is presented in Figure 9. All processes are assumed to be co-located, while investment planning is neglected. A preliminary version of the case study was presented in [62].

\subsection{Input data and structuring}

\subsubsection{Surrogate process models}

A surrogate model of a gas turbine (GT) and a bottoming steam Rankine cycle (SR) were developed based on data from the Danish back-pressure combined cycle CHP plant 'Silkeborg Kraftvarmeværk' [63]. In the surrogate models, temperature levels were assumed to be load-independent, while gas consumption, GT power generation, and off-gasses heat flow capacity were assumed to be directly proportional to the GT load $\lambda_{G T}$. The heat and power generation of the SR were assumed directly proportional to the SR load $\lambda_{S R}$. Both the GT and the SR were assumed to operate adiabatically. Data used for developing the GT and SR surrogate models are presented in Table 1.

A surrogate model of an IBUS ethanol facility (IB) was developed based on a validated IBUS facility model by Lythcke-Jørgensen et al. [14][64], with the modification that thermal separation stages were replaced by mechanical separation stages. A surrogate model of a biomethane facility (AD), consisting of a thermophilic anaerobic digestion reactor operating at $55^{\circ} \mathrm{C}$ and a biogas upgrading facility, was developed based on models presented by Evald et al. [65]. The IB and the AD were assumed to have zero load flexibility.

Surrogate models of a gas boiler (GB), a biomass boiler (BB), and a district heating heat pump (HP) were developed based on data presented by the Danish Energy Agency [66].

Economic data on the surrogate models are presented in Table 2. In the calculations, a plant lifetime of $y_{l t}=30$ years and an annual discount rate of $i=0.06$ were assumed. For power law investment calculations as defined in equation (11), an investment scaling constant of $M_{f}=0.75$ was used. 
Thermal energy flows as functions of process variables are presented in Table 3. It was assumed that a cold water reservoir with a temperature of $15^{\circ} \mathrm{C}$ was available for balancing heat flows in the system. As all processes were considered to be co-located, a single thermal energy layer was defined in the model.

Mass flows in the various layers as functions of process variables are presented in Tables 4-8. Note that power flows were modelled as mass flows in a separate layer. Market surrogate models were introduced 600 into each layer to ensure mass balances.

\subsubsection{Energy system, market, and environmental impact data}

602

For the case study, the power price $c_{e l}$ and the relative district heating demand $\lambda_{D H}$ were identified as

relevant external operating parameters. A CHOP-reduced dataset of $c_{e l}$ and $\lambda_{D H, r e f}$ based on historical data for western Denmark over the period primo 2010-ultimo 2014 has been presented by LythckeJørgensen et al. [49]. This dataset was applied in the present case study as representative for operating conditions over the lifetime of the studied FMG. The CHOP-reduced dataset is presented in Tables 9-12. A scatter plot of original and reduced operating condition data points is presented in Figure 10.

For simplicity, the environmental objective of the study only considered $\mathrm{CO}_{2}$-emissions from facility production and avoided $\mathrm{CO}_{2}$-emissions from displaced external production. Average emission values were in general applied for the displaced production. Marginal values may, however, be utilised, e.g. in combination with energy system analysis [67]. Economic and environmental data on consumed and sold products are presented in Table 13. Biomass was assumed to be $\mathrm{CO}_{2}$ neutral. Manure was assumed to be delivered free of charge by local farmers in exchange for free, digested fertilizer. Manure emission impacts were not considered, although anaerobic digestion of manure may reduce greenhouse gas emissions significantly as compared to conventional use of undigested manure as fertilizer.

\subsubsection{Biomass supply chain model}

617 Apart from the straw cost paid to the producers as indicated in Table 13, an additional cost was placed on 
reported a fixed cost of 1.07 Euro/GJ for straw logistics in Denmark, including transportation for up to 10 $\mathrm{km}$, while an additional cost of $0.009 \mathrm{Euro} /(\mathrm{GJ} / \mathrm{km})$ is charged for every additional kilometre. Assuming a mean winter wheat straw yield of $4,183 \mathrm{~kg} / \mathrm{ha}$, as suggested by Bentsen et al. [74], and that $20 \%$ of the area around the facility has winter wheat cultivation, a surrogate biomass supply chain model was developed. The model is presented in Table 14. It was not assumed feasible to import biomass from outside the $50 \mathrm{~km}$ radius area around the facility.

\subsubsection{Optimization constraints}

Design variables and constraints in the case study are summarized in Table 15. As previously mentioned, investment planning was not considered in the present case. considered a back-up utility, it was dimensioned in the operation optimization step based on maximum required load. Note that the ethanol facility and the combined biogas facility were assumed to be inflexible, 631 implying that load variations are not considered in the operation optimization. The facility was considered 632 to be the sole provider of heating for the district heating grid, and, consequently, the district heating 633 generation must meet the demand at all times.

$$
\lambda_{D H} \equiv \lambda_{D H, r e f}
$$

635 In the optimization phase, the genetic algorithm was run for a population size of 50 over 5 generations.

\subsubsection{Sensitivity and uncertainty analysis}

637 The uncertain input parameters considered in the case study and their distributions are given in Table 17.

638 The reference investment costs and the ethanol price were given a relative uncertainty of $\pm 25 \%$ with a 639 uniform distribution to represent cost and market uncertainties. The $\mathrm{CO}_{2}$ emissions displaced from the 640 ethanol produced $z_{e t h}$ was assumed to vary in the range $[0 \%,-40 \%]$ with a uniform distribution to 641 represent the facts that it may not be gasoline that is replaced by the produced ethanol, and that the straw 
consumed may not be $\mathrm{CO}_{2}$ neutral. Finally, the investment scaling constant was given an uncertainty range 643 of $[0.6,0.9]$ with a uniform distribution to represent the uncertainties related to the economy of scale 644 benefits from investments.

645 Morris screening was conducted with $\{b, w\}=\{8,35\}$. For each Monte Carlo simulation, a sample of 250 646 data points was generated using Latin Hypercube Sampling [60] and assuming zero correlation between 647 uncertainties in input parameters.

\subsection{Results and evaluation}

649 A database of feasible designs with optimized operation was obtained from running the optimization model. 650 A scatter plot of the optimized designs with respect to NPV and $\mathrm{CO}_{2}$ emission impact is shown in Figure 11. 651 In general, it was found that the larger the dimension of the biomass treatment facilities, the lower the NPV and the lower the total $\mathrm{CO}_{2}$ emission impact, illustrating the cost of avoided $\mathrm{CO}_{2}$ emissions in the case study. It was further found that the cost of avoided $\mathrm{CO}_{2}$ emission was higher for designs including both ethanol and biomethane production than for designs with only ethanol production. This trend is primarily caused by two effects: First of all, avoided $\mathrm{CH}_{4}$ emissions from undigested manure were not considered in the calculations, which would expectedly reduce the total $\mathrm{CO}_{2}$ emission impacts from designs with biogas production significantly. Secondly, a GB was installed as back-up utility heat source, and it was used in periods where it was economically unfavourable to operate the gas turbine while power for running the operation was imported from the grid. Combined, this made the overall biomethane production unfavourable from both an economic and an environmental perspective in the case study.

The results further indicate that the NPV is reduced while the $\mathrm{CO}_{2}$ emission impact is only slightly affected for larger biomass boiler dimensions, suggesting that the biomass boiler is hardly used in the operation optimization for economic reasons. This opposes the current (2015) trend in Denmark where biomass, which is currently tax free, is replacing the taxed natural gas in the heating sector. The reason for this 
666

suggest that operation with a district heating heat pump is favourable for specific periods, but that the investment costs make the overall economic performance of heat pumps unfavourable. Again, it must be stressed that taxes and subsidy schemes were not considered in the calculations.

Three interesting designs, $I, I I$, and $I I I$, were chosen for further investigation. Here, $I$ is the identified retrofit design with the highest NPV; II is the identified retrofit design with the lowest $\mathrm{CO}_{2}$-emission impact; and III is the retrofit design with the largest NPV that includes biomethane production. The characteristics of the designs are described in Table 18, together with the performance of the reference facility (Ref).

Based on the input parameter uncertainties defined in Table 17, Morris screening was applied for identifying elementary effects on NPV and GWP100a from each of the uncertain input parameters in each of the three selected designs. An example of an elementary effect histogram obtained using Morris screening is plotted in Figure 12.

The means and standard deviation of the sigma-scaled elementary effects from uncertain input parameters on each of the model outputs are plotted for the three selected designs in Figure 13. The wedges in the figures represent the standard error of the mean as defined in equation (25). Elementary effects with mean and standard deviations of zero are not labelled in the figures.

The scatter plots illustrate the relative importance of each of the input parameter uncertainties on each of the model outputs. From Figure 13, it is seen that the NPV of design / would be significantly affected by uncertainties in reference ethanol facility investment $\operatorname{cost} C_{i n v, I B 0}$ and investment scaling constant $M_{f}$, as the mean and standard deviations of their elementary effects' on NPV are far outside the standard-errorof-the-mean wedge. Furthermore, it is seen that the impacts of $C_{i n v, I B 0}$ and $M_{f}$ are either correlated with other uncertain input parameters, non-linear, or both, as their standard deviations are different from zero. The ethanol price $c_{e t h}$ on the other hand was found to have a linear impact on NPV as the elementary effect has a standard deviation of zero. These observations can easily be confirmed by investigating the model structure. It is further seen that the NPV of design I was neither affected by the displaced $\mathrm{CO}_{2}$ 
emission from ethanol $z_{\text {eth }}$ nor the reference investment costs of the biomethane facility $C_{i n v, A D 0}$ and district heating heat pump $C_{i n v, H P 0}$. This is evident from the fact that the dimension of the heat pump was negligible, no combined biogas facility was installed, and no economic cost was associated with $\mathrm{CO}_{2}$ emissions. Opposed to this, as expected, $z_{\text {eth }}$ is found to be the only parameter affecting the total $\mathrm{CO}_{2}$ emission impact.

Similarly, observations on impact of parameter uncertainties were made for designs II and III based on Figure 13. For II, it was found that $c_{e t h}$ had significantly more impact than the other designs. This is due to the fact that the ethanol facility was markedly larger, causing ethanol sales to have a relatively larger impact on the NPV. For III, it was found that $C_{i n v, A D 0}$ was no longer negligible, as a biomethane facility was in fact installed.

Based on the Morris screening results, Monte Carlo simulations were conducted for each of the three designs considering non-negligible uncertainties in input parameters. The parameters considered are summarized in Table 19. The Latin Hypercube Sampling method was applied for generating samples of each 250 data points for use in the Monte Carlo simulations. A visual representation of the Latin Hypercube sample used in the Monte Carlo simulation for design / is presented in Figure 14.

Running Monte Carlo simulations for each of the three selected designs, the resulting $10^{\text {th }}$ to $90^{\text {th }}$ percentile interval of predicted NPV and $0^{\text {th }}$ to $90^{\text {th }}$ percentile interval of predicted GWP100a are indicated for each of the three selected designs in Figure 15.

The figure illustrates the variability in performance of the selected designs as functions of the defined input uncertainty. It is seen how the NPV variation is somewhat evenly distributed around the predicted value, which is to be expected as uncertainties in economic parameters are all considered to be evenly and uniformly distributed around the reference value. It is furthermore seen that the predicted $\mathrm{CO}_{2}$ emission impact in the deterministic run is the lowest possible as the considered uncertainties in $\mathrm{CO}_{2}$ emission impact can only lead to higher $\mathrm{CO}_{2}$ emission impacts. 
714 In general, the performance variations are found to be larger for design II, caused by larger retrofit 715 investments and a larger ethanol production, implying that the relative uncertainties in investments, 716 ethanol prices and replaced $\mathrm{CO}_{2}$ emissions from produced ethanol will have a larger impact in absolute 717 terms.

718 Even with $10^{\text {th }}$ to $90^{\text {th }}$ percentile intervals, design / will outperform design III with respect to NPV, whereas 719 the total $\mathrm{CO}_{2}$ emission impact is somewhat similar, suggesting that III should not be selected for the given 720 case. Considering the found performance intervals, design / has a $\mathrm{CO}_{2}$ reduction price of 4.9-30.3 Euro/ton, 721 while design $/ /$ has a $\mathrm{CO}_{2}$ reduction price of 8.4-32.1 Euro/ton. Hence, in the marginal case, the results 722 suggest that design / should be preferred if cost-efficient $\mathrm{CO}_{2}$ reductions are desired.

723 A central aspect of the design methodology is the application of systematic process integration. To assess 724 the importance of this feature, the performances of each of the three selected designs were evaluated 725 without consideration of process integration, i.e. the combined cycle CHP and the biomass treatment 726 facilities were operated separately. The change in performance is illustrated in Figure 16.

727 It is clear that without process integration, all three designs obtained lower NPV and higher $\mathrm{CO}_{2}$ emission 728 impacts. Also, it appears that the larger the dimensions of the biomass processing equipment, the larger 729 the absolute reduction in performance. Altogether, this demonstrates the importance of considering 730 process integration, both when developing smart energy systems in general and when designing FMGs in 731 particular.

\section{4. Discussion and perspective}

733 This paper presents a generic methodology for optimizing the design of flexible multi-generation systems 734 (FMGs), which are systems consisting of integrated and flexibly operated facilities that together provide 735 multiple links between layers of the energy system. 
One of the challenges of the presented design methodology is the fact that it is based on partial analysis, which implies that the impact on system level of FMG operation is neglected. However, as the central hypotheses for FMGs consider impacts on system levels, it is crucial that the aggregated impact of FMGs is assessed. For instance, if a number of FMGs are set to balance the power system by generating electricity in periods with no generation from renewable sources, they may become market dominating and thereby affect the power prices - a situation that makes partial analysis insufficient. One way of assessing the aggregated impact of FMG operation is to apply the developed design methodology for identification of preliminary designs of FMGs, and then integrate these designs in an energy system model in order to assess the system impact. The results from the energy system analysis could then be provided as feedback to the design methodology in an iterative loop. This topic will be treated in future research by the group.

One of the shortcomings of the design methodology is the fact that thermal storages and dynamic operation constraints cannot be considered due to the application of the CHOP method [49]. The latter is applied to reduce computation times when searching for optimal designs while still maintaining detailed information on flexible operating conditions, which was previously proven to be crucial for obtaining optimal designs [62]. An advantage of the CHOP method is the fact that it is capable of capturing non-cyclic patterns in the energy system as opposed to most other energy system data aggregation methods, e.g. standard days, standard periods, average periods etc. [49]. To overcome the shortcoming of dynamic operation, the optimization phase of the methodology can be divided into two parts: A preliminary part where CHOP-reduced energy system data are used for the preliminary design, and a second part where chronological energy system data are used for detailed design and performance evaluation. This is analogous to the methodology presented by Rubio-Maya et al. [29], [30]. The second step would then allow for the consideration of thermal energy storages and dynamic operational constraints, albeit at the cost of increased computational time. Whether or not this is the right way to proceed is a relevant topic for further investigation. 
In the design methodology, a genetic algorithm is used as the master algorithm to be able to digest all sorts of models and scan the solution space for efficient solutions. However, being heuristic by nature, it cannot guarantee optimality of the solutions. For example, in the simple case study considered, the optimized retrofit design with the highest NPV, ' $l$ ', had a biomass boiler of $1.1 \mathrm{MJ} / \mathrm{s}$ and a heat pump of $0.3 \mathrm{MJ} / \mathrm{s}$ installed, while the ethanol facility straw processing capacity was $5.2 \mathrm{~kg} / \mathrm{s}$. If the biomass boiler and heat pumps are removed, and the ethanol facility dimension is reduced to the minimum, i.e. $5.0 \mathrm{~kg} / \mathrm{s}$, the NPV would increase from 14.6 MEuro to 24.5 MEuro. This illustrates one of the drawbacks of using genetic algorithms: They may approximate the optimal or efficient solutions, but are not guaranteed to find them. However, as the present methodology is focussed on pre-feasibility studies of FMGs, the genetic algorithm is considered advantageous as it efficiently 'separates the wheat from the chaff'.

One of the novelties of the method is the consideration of local biomass supply chains, which is likely to have an impact on the dimensioning of biomass-processing FMGs [50]. In a similar manner, local industry and its demand for process heat, cooling, and other energy services ought to be considered when designing FMGs. If local industry is systematically considered for process integration in FMG studies, the overall energy and exergy efficiency of the local community may be increased further, and the industry demands may impact the dimensioning of FMGs as well. Thus, FMGs may be considered as supply facilities in local energy hubs or industrial symbioses, characterized by a high degree of mass and energy integration and reduced environmental impacts when compared to stand-alone industry.

In general, it is relevant to allow for future retrofit options when designing complex systems like FMGs, as discussed by Liu and Pistikopoulos [22]. However, inclusion of investment planning in the design methodology is challenging as both technological and system developments are hard to predict. Whether or not investment planning should be considered in pre-feasibility analysis depends on the case treated, but it is evident that the computational time would increase exponentially as multiple investment scenarios would have to be considered by the genetic algorithm. 
Economic and environmental parameter uncertainties are efficiently handled in the design methodology using a combined Morris screening/Monte Carlo simulation approach. With regard to handling of energy system uncertainties in the design methodology, it is recommended that explorative scenarios are used to give a better overview of optimality differences between likely, but fundamentally different, energy system scenarios. It should be noted that the total computation time is approximately proportional to the number of scenarios investigated in the developed design methodology. In the present study, it took approximately 84 hours to conduct all calculations on a laptop with an Intel ${ }^{\circledast}$ Core $^{\mathrm{TM}}$ i7-3720QM CPU @ $2.60 \mathrm{GHz}$ considering one energy system scenario.

The present case study featured a socio-economic analysis as neither taxes nor subsidies were considered. In general, socio-economic analyses can be used for providing recommendations for policy makers. If the design methodology is used with the aim of guiding investment decisions, it would be relevant to conduct a private economic evaluation including taxes and subsidies.

A significant outcome of the case study is the assessment of impact from systematic process integration in the design methodology. The results show how the selected designs become suboptimal when process integration is neglected, and thus underline the importance of including process integration when developing smart energy systems in general and when designing FMGs in particular.

\section{Conclusion}

A generic methodology for optimizing the design of FMGs is presented which simultaneously consider the following issues: Selection, location, and dimensioning of processes; systematic heat and mass integration; flexible operation optimization with respect to both short-term market fluctuations and long-term energy system development; global sensitivity and uncertainty analysis; consideration of local biomass availability and biomass supply chains; variable part-load performance; investment planning; and multi-objective optimization considering net present value (NPV) and 100-years global warming potential (GWP100a). 
The methodology was applied in a simple case study where cellulosic ethanol production and upgraded biogas production were considered for installation in an existing combined cycle combined heat and power plant. The integration of ethanol production yielded more efficient results with respect to NPV and total $\mathrm{CO}_{2}$ emission impact than did the integration of combined ethanol and biomethane production. However, the total $\mathrm{CO}_{2}$ emission impact might conceivably have been reduced significantly for designs with biomethane production if avoided $\mathrm{CH}_{4}$ emissions from conventional use of manure had been considered. The highest NPV and $\mathrm{CO}_{2}$ emission impact was obtained for the reference combined heat and power plant, illustrating that reducing $\mathrm{CO}_{2}$ emissions come at a cost. The case study further demonstrated how suboptimal designs would be obtained if systematic process integration was not considered, underlining the importance of considering systematic process integration when developing smart energy systems in 817 general, and FMGs in particular.

818 The developed design methodology efficiently screens the solution space for promising FMG designs, and 819 is capable of assessing the importance of parameter uncertainties as well as estimating the likely performance variation for the individual designs. Thus, the developed design methodology is useful for conducting quick and reliable pre-feasibility analyses for the development of FMG concepts.

\section{Acknowledgements}

823 This research was supported by DONG Energy and the Innovation Foundation through the 4DH project. The 824 authors thank prof. Gürkan Sin, DTU Chemical Engineering, CAPEC-PROCESS, for fruitful discussions on 825 sensitivity and uncertainty analysis, and for allowing the use of his Matlab programs for conducting Morris screening and Monte Carlo simulations. The authors also thank Ida Græsted Jensen, DTU Management Engineering, Systems Analysis, for fruitful discussions on the modelling of biomass supply chains. Finally, the authors would like to thank Bodil Diemer for linguistic comments and suggestions that greatly improved the manuscript. 


\section{References}

831 [1] G. Chicco and P. Mancarella, "Distributed multi-generation: A comprehensive view," Renewable and Sustainable Energy Reviews, vol. 13, no. 3. pp. 535-551, 2009.

[2] H. Song, F. Starfelt, L. Daianova, and J. Yan, "Influence of drying process on the biomass-based polygeneration system of bioethanol, power and heat," Appl. Energy, vol. 90, no. 1, pp. 32-37, 2012.

[3] H. Lund, A. N. Andersen, P. A. Østergaard, B. V. Mathiesen, and D. Connolly, "From electricity smart grids to smart energy systems - A market operation based approach and understanding," Energy, vol.

[4] M. Geidl, G. Koeppel, P. Favre-Perrod, B. Klöckl, G. Andersson, and K. Fröhlich, “Energy hubs for the 839

[6] H. Lund, F. Hvelplund, P. Østergaard, B. Möller, B. V. Mathiesen, D. Connolly, and A. N. Andersen, Renewable Energy Systems. 2014.

[7] H. Lund, Renewable Energy Systems: The Choice and Modeling of 100\% Renewable Solutions. Academic Press publications, 2010.

[8] Z. Yuan and B. Chen, "Process synthesis for addressing the sustainable energy systems and

[9] L. M. Serra, M.-A. Lozano, J. Ramos, A. V. Ensinas, and S. A. Nebra, "Polygeneration and efficient use of natural resources," Energy, vol. 34, no. 5. pp. 575-586, 2009.

[10] W. Zhou, H. Yang, M. Rissanen, B. Nygren, and J. Yan, “Decrease of energy demand for bioethanolbased polygeneration system through case study," Appl. Energy, vol. 95, pp. 305-311, 2012.

[11] P. Ahmadi, I. Dincer, and M. a. Rosen, “Development and assessment of an integrated biomassbased multi-generation energy system," Energy, vol. 56, pp. 155-166, 2013.

[12] B. V. Mathiesen, H. Lund, D. Connolly, H. Wenzel, P. a. Østergaard, B. Möller, S. Nielsen, I. Ridjan, P. 
Karnøe, K. Sperling, and F. K. Hvelplund, "Smart Energy Systems for coherent 100\% renewable energy and transport solutions," Appl. Energy, vol. 145, pp. 139-154, 2015.

[13] P. Mancarella, "MES (multi-energy systems): An overview of concepts and evaluation models," Energy, vol. 65. pp. 1-17, 2014.

[14] C. Lythcke-Jørgensen, F. Haglind, and L. R. Clausen, "Exergy analysis of a combined heat and power plant with integrated lignocellulosic ethanol production," Energy Convers. Manag., vol. 85, pp. 817827, 2014.

[15] M. Gassner and F. Maréchal, "Methodology for the optimal thermo-economic, multi-objective design of thermochemical fuel production from biomass," Comput. Chem. Eng., vol. 33, no. 3, pp. 769-781, 2009.

[16] L. Gerber, M. Gassner, and F. Maréchal, "Systematic integration of LCA in process systems design: Application to combined fuel and electricity production from lignocellulosic biomass," Comput. Chem. Eng., vol. 35, no. 7, pp. 1265-1280, 2011.

[17] L. Tock and F. Maréchal, "Co-production of hydrogen and electricity from lignocellulosic biomass: Process design and thermo-economic optimization," Energy, vol. 45, no. 1, pp. 339-349, 2012.

[18] P. Liu, D. I. Gerogiorgis, and E. N. Pistikopoulos, “Modeling and optimization of polygeneration energy systems," Catal. Today, vol. 127, no. 1-4, pp. 347-359, 2007.

[19] P. Liu, E. N. Pistikopoulos, and Z. Li, “A mixed-integer optimization approach for polygeneration energy systems design," Comput. Chem. Eng., vol. 33, no. 3, pp. 759-768, 2009.

[20] P. Liu and E. N. Pistikopoulos, “A Multi-Objective Optimization Approach to Polygeneration Energy Systems Design," AIChE J., vol. 56, no. 5, pp. 1218-1234, 2010.

[21] P. Liu, E. N. Pistikopoulos, and Z. Li, “Decomposition Based Stochastic Programming Approach for Polygeneration Energy Systems Design under Uncertainty," Ind. Eng. Chem. Res., vol. 49, no. 7, pp. 3295-3305, 2010.

[22] P. Liu, E. N. Pistikopoulos, and Z. Li, "Polygeneration Systems Engineering," in Process Systems 
Engineering, vol. 5, 2011, pp. 1-38.

[23] Y. Chen, T. A. Adams, and P. I. Barton, "Optimal design and operation of static energy polygeneration systems," Ind. Eng. Chem. Res., vol. 50, no. 9, pp. 5099-5113, 2011.

[24] Y. Chen, T. A. Adams, and P. I. Barton, "Optimal design and operation of flexible energy polygeneration systems," Ind. Eng. Chem. Res., vol. 50, no. 8, pp. 4553-4566, 2011.

[25] Y. Chen, X. Li, T. A. Adams II, and P. I. Barton, "Decomposition Strategy for the Global Optimization of Flexible Energy Polygeneration Systems," AlChE, vol. 58, no. 10, pp. 3080-3095, 2012.

[26] M. Tawarmalani and N. V. Sahinidis, "Global optimization of mixed-integer nonlinear programs: A theoretical and computational study," Math. Program., vol. 99, no. 3, pp. 563-591, 2004.

[27] Y. Chen, "Optimal design and operation of energy polygeneration systems," 2013.

[28] C. Marnay, G. Venkataramanan, M. Stadler, A. S. Siddiqui, R. Firestone, and B. Chandran, "Optimal technology selection and operation of commercial-building microgrids," IEEE Trans. Power Syst., vol. 23, no. 3, pp. 975-982, 2008.

[29] C. Rubio-Maya, J. Uche-Marcuello, A. Martínez-Gracia, and A. a. Bayod-Rújula, “Design optimization of a polygeneration plant fuelled by natural gas and renewable energy sources," Appl. Energy, vol. 88, no. 2, pp. 449-457, 2011.

[30] C. Rubio-Maya, J. Uche-Marcuello, and A. Martínez-Gracia, "Sequential optimization of a polygeneration plant," Energy Convers. Manag., vol. 52, no. 8-9, pp. 2861-2869, 2011.

[31] A. Piacentino, C. Barbaro, F. Cardona, R. Gallea, and E. Cardona, "A comprehensive tool for efficient design and operation of polygeneration-based energy micro-grids serving a cluster of buildings. Part I: Description of the method," Appl. Energy, vol. 111, pp. 1204-1221, 2013.

[32] T. Capuder and P. Mancarella, "Techno-economic and environmental modelling and optimization of flexible distributed multi-generation options," Energy, vol. 71, pp. 516-533, 2014.

[33] T. Capuder and P. Mancarella, "Modelling and Assessment of the Techno-economic and Environmental Performance of Flexible Multi- Generation Systems," 18th Power Syst. Comput. Conf. 
Wroclaw, Pol., 2014.

[34] E. Martínez Ceseña, T. Capuder, and P. Mancarella, "Flexible Distributed Multienergy Generation System Expansion Planning Under Uncertainty," IEEE Trans. Smart Grid, pp. 1-10, 2015.

[35] P. Voll, M. Lampe, G. Wrobel, and A. Bardow, "Superstructure-free synthesis and optimization of distributed industrial energy supply systems," Energy, vol. 45, no. 1, pp. 424-435, 2012.

[36] P. Voll, C. Klaffke, M. Hennen, and A. Bardow, “Automated superstructure-based synthesis and optimization of distributed energy supply systems," Energy, vol. 50, no. 1, pp. 374-388, 2013.

[37] B. Meyer, P. Voll, S. Kirschbaum, and A. Bardow, "MILP Optimization of Nonlinear Energy Systems by Multivariate Piecewise-Affine Surrogate Modeling," in Proceedings of the 26th International Conference on Efficiency, Cost, Optimization, Simulation and Environmental Impact of Energy Systems, 2013.

[38] P. Voll, M. Hennen, C. Klaffke, M. Lampe, and A. Bardow, "Exploring the near-optimal solution space for the synthesis of distributed energy supply systems," Chem. Eng. Trans., vol. 35, pp. 277-282, 2013.

[39] P. Petruschke, G. Gasparovic, P. Voll, G. Krajačić, N. Duić, and A. Bardow, "A hybrid approach for the efficient synthesis of renewable energy systems," Appl. Energy, 2014.

[40] Z. Zhou, J. Zhang, P. Liu, Z. Li, M. C. Georgiadis, and E. N. Pistikopoulos, “A two-stage stochastic programming model for the optimal design of distributed energy systems," Appl. Energy, vol. 103, pp. 135-144, 2013.

[41] M. Leung Pah Hang, E. Martinez-Hernandez, M. Leach, and A. Yang, "Engineering Design of Localised Synergestic Production Systems," in 25th European Symposium on Process Systems Engineering and 25th Symbposium on Computer Aided Process Engineering, 2015.

[42] C. Lythcke-Jørgensen and F. Haglind, “Design optimization of a polygeneration plant producing power, heat , and lignocellulosic ethanol," Energy Convers. Manag., vol. 91, pp. 353-366, 2015.

[43] F. Maréchal, C. Weber, and D. Favrat, "Multiobjective Design and Optimization of Urban Energy 
Systems," in Process Systems Engineering, 2011, pp. 39-83.

[44] S. Fazlollahi and F. Maréchal, "Multi-objective, multi-period optimization of biomass conversion technologies using evolutionary algorithms and mixed integer linear programming (MILP)," Appl. Therm. Eng., vol. 50, no. 2, pp. 1504-1513, 2013.

[45] S. Fazlollahi, G. Becker, and F. Maréchal, "Multi-objectives, multi-period optimization of district energy systems: I. Selection of typical operating periods," Comput. Chem. Eng., vol. 65, pp. 54-66, 2014.

[46] S. Fazlollahi, G. Becker, and F. Maréchal, "Multi-objectives, multi-period optimization of district energy systems: II-Daily thermal storage," Comput. Chem. Eng., vol. 71, pp. 648-662, 2014.

[47] S. Fazlollahi, G. Becker, and F. Maréchal, "Multi-objectives, multi-period optimization of district energy systems: III. Distribution networks," Comput. Chem. Eng., vol. 66, pp. 82-97, 2014.

[48] R. Bolliger, "Méthodologie de la synthèse des systèmes énergétiques industriels," 2010.

[49] C. Lythcke-Jørgensen, F. Haglind, A. V. Ensinas, and M. Münster, "A method for aggregating external operating conditions in multi-generation plant optimization models," Appl. Energy, vol. under revi, 2015.

[50] M. W. Jack, "Scaling laws and technology development strategies for biorefineries and bioenergy plants," Bioresour. Technol., vol. 100, no. 24, pp. 6324-6330, 2009.

[51] R. Smith, Chemical process design and integration. Chister, West Sussex, England: John Wiley \& Sons Ltd, 2005.

[52] A. Boldrin, K. R. Baral, T. Fitamo, A. H. Vazifehkhoran, I. G. Jensen, I. Kjærgaard, Q. Van Nguyen, K.-A. Lyng, L. Skovsgaard Nielsen, and J. M. Triolo, “A dynamic model for integrated optimization of Biogas Production - A case study on Sugar Beet Biomass," Energy, vol. (in proces, 2015.

[53] S. Fazlollahi, P. Mandel, G. Becker, and F. Maréchal, "Methods for multi-objective investment and operating optimization of complex energy systems," Energy, vol. 45, no. 1, pp. 12-22, 2012.

[54] R. L. Haupt and S. E. Haupt, Practical Genetic Algorithms. John Wiley \& Sons, Inc., 2006. 
[55] I. C. Kemp, Pinch Analysis and Process Integration. 2006.

[56] R. Turton, R. C. Bailie, W. B. Whiting, and J. a. Shaeiwitz, Analysis, Synthesis, and Design of Chemical Processes. 1998.

[57] M. D. Morris, "Factorial Sampling Plans for Preliminary Computational Experiments," Technometrics, vol. 33, no. 2, pp. 161-174, 1991.

[58] G. Sin, K. V. Gernaey, and A. E. Lantz, "Good modeling practice for PAT applications: Propagation of input uncertainty and sensitivity analysis," in Biotechnology Progress, 2009, vol. 25, no. 4, pp. 10431053.

[59] J. C. Helton and F. J. Davis, "Latin hypercube sampling and the propagation of uncertainty in analyses of complex systems," Reliability Engineering and System Safety, vol. 81, no. 1. pp. 23-69, 2003.

[60] M. D. McKay, R. J. Beckman, and W. J. Conover, "Comparison of three methods for selecting values of input variables in the analysis of output from a computer code," Technometrics, vol. 21, no. 2, pp. 239-245, 1979.

[61] J. Larsen, M. Ø. Haven, and L. Thirup, "Inbicon makes lignocellulosic ethanol a commercial reality," Biomass and Bioenergy, vol. 46, pp. 36-45, 2012.

[62] C. Lythcke-Jørgensen, M. Münster, A. V Ensinas, and F. Haglind, “Design optimization of flexible biomass-processing polygeneration plants using characteristic operation periods," in World Renewable Energy Congress XIII, 2014.

[63] "Silkeborg Forsyning." [Online]. Available: http://www.silkeborgforsyning.dk/. [Accessed: 13-Sep2015].

[64] C. Lythcke-Jørgensen, “Modelling and Optimization of a Steam Co-generation Plant with Integrated Bio-ethanol Production," Technical University of Denmark, 2012.

[65] A. Evald, G. Hu, and M. T. Hansen, "Technology data for advanced bioenergy fuels," 2013.

[66] Energinet.dk and Danish Energy Agency, Technology data for energy plants, no. January 2014. 2012.

[67] M. Münster and P. Meibom, "Long-term affected energy production of waste to energy technologies 
identified by use of energy system analysis," Waste Manag., vol. 30, no. 12, pp. 2510-2519, 2010.

981

982

983

984

985

986

987

988

989

990

991

992

993

994

995

996

997

998

999
[68] Danish Energy Agency, “FORUDSAETNINGER FOR SAMFUNDS ØKONOMISKE ANALYSER PÅ ENERGIOMRÅDET," 2014.

[69] Ipcc, 2006 IPCC Guidelines for National Greenhouse Gas Inventories, vol. 4. 2006.

[70] COWI, “FJERNVARMEANALYSE - BILAGSRAPPORT," 2014.

[71] Danish Energy Agency, “Danske nøgletal," 2015. [Online]. Available: http://www.ens.dk/info/talkort/statistik-nogletal/nogletal/danske-nogletal.

[72] J. Larsen, M. Øtergaard Petersen, L. Thirup, H. W. Li, and F. K. Iversen, “The IBUS process Lignocellulosic bioethanol close to a commercial reality," Chem. Eng. Technol., vol. 31, no. 5, pp. 765-772, 2008.

[73] E. Energianalyse, “Opdatering af samfundsøkonomiske brændselspriser - BIOMASSE," 2011.

[74] N. S. Bentsen, C. Felby, and K. H. Ipsen, "Energy balance of 2nd generation bioethanol production in Denmark," Dong Energy R. Vet. Agric. Univ. Danish Cent. For. Landsc. Plan., 2006.

[75] T. A. Adams and J. H. Ghouse, "Polygeneration of fuels and chemicals," Curr. Opin. Chem. Eng., vol. 10, pp. 87-93, 2015.

[76] E. Souleimanov and J. Kraus, "Turkey: An Important East-West Energy Hub," Middle East Policy, vol. 19, no. 2, pp. 157-168, 2012.

[77] K. Hemmes, J. L. Zachariah-Wolf, M. Geidl, and G. Andersson, "Towards multi-source multi-product energy systems," Int. J. Hydrogen Energy, vol. 32, no. 10-11, pp. 1332-1338, 2007. 


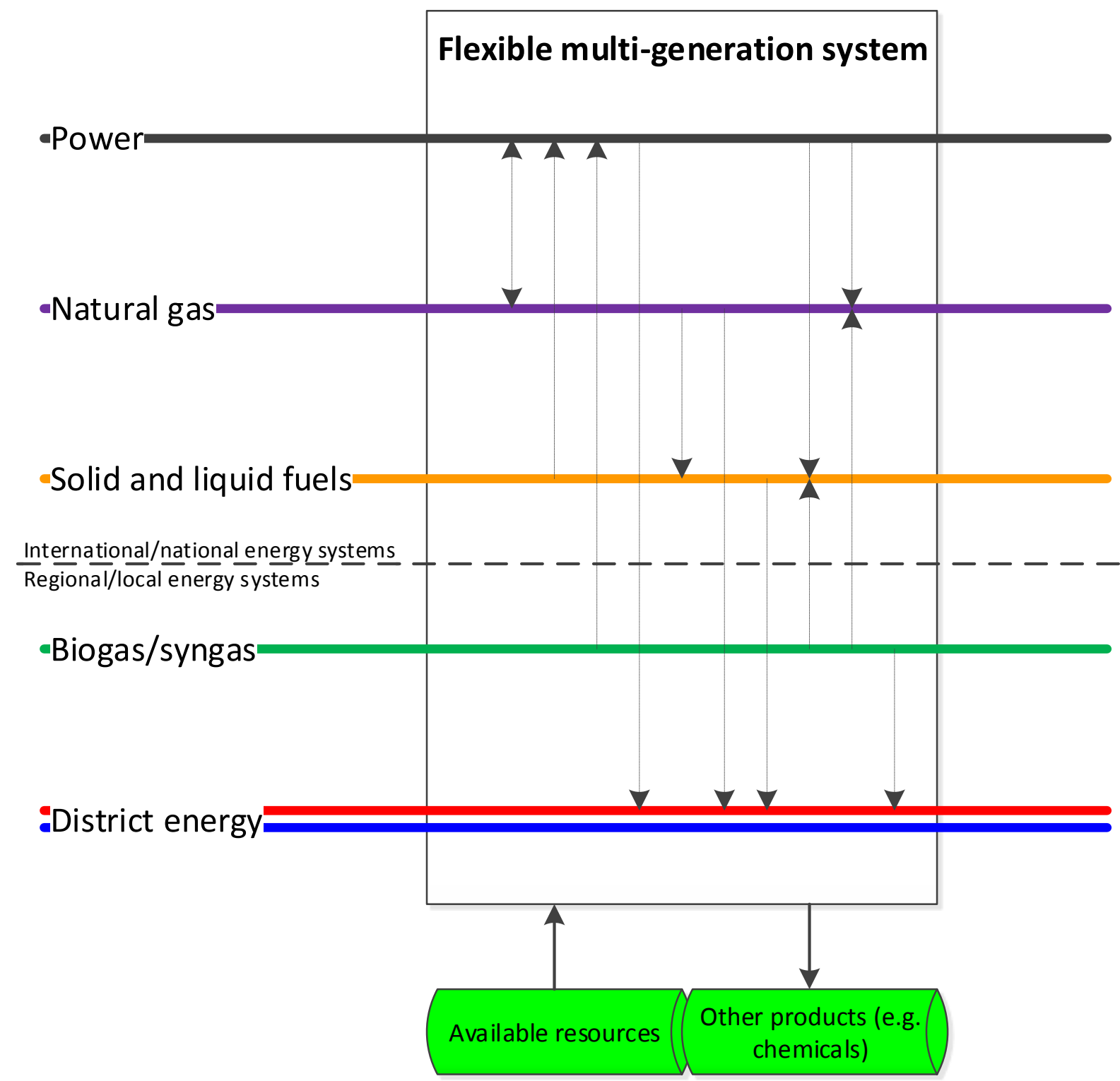

Figure 1: Conceptual sketch of a flexible multi-generation system. Dotted arrows indicate a range of technological pathways for linking the energy system layers. 


\section{Macro}

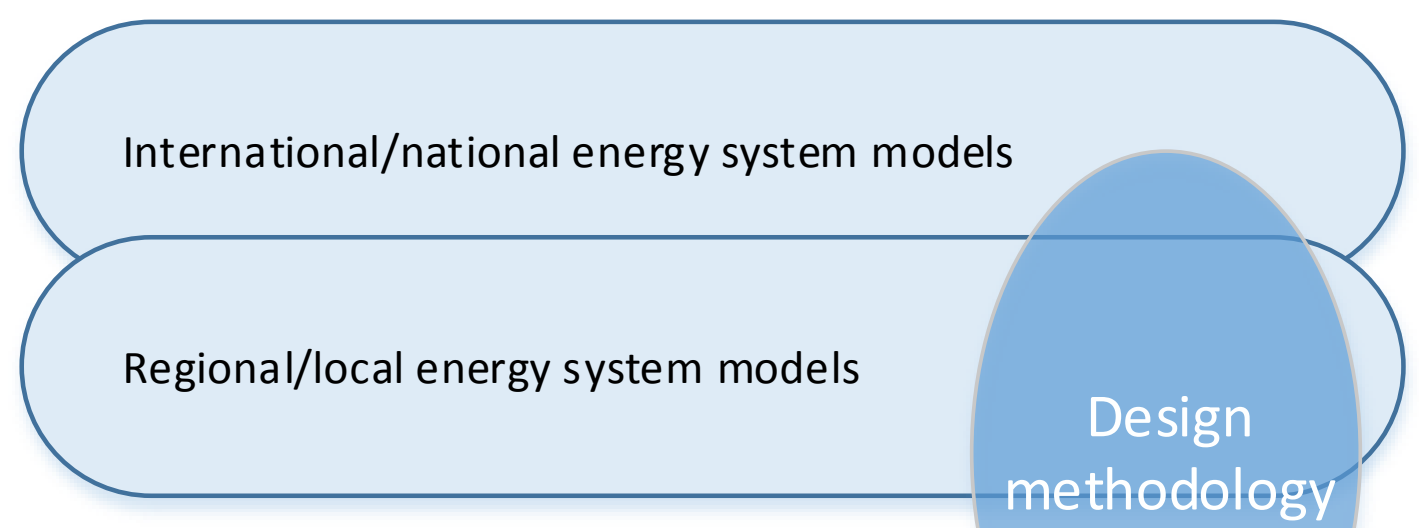

Thermodynamic process and plant models

\section{Micro}

Figure 2: Visualization of how the design methodology interacts with models at various levels. 


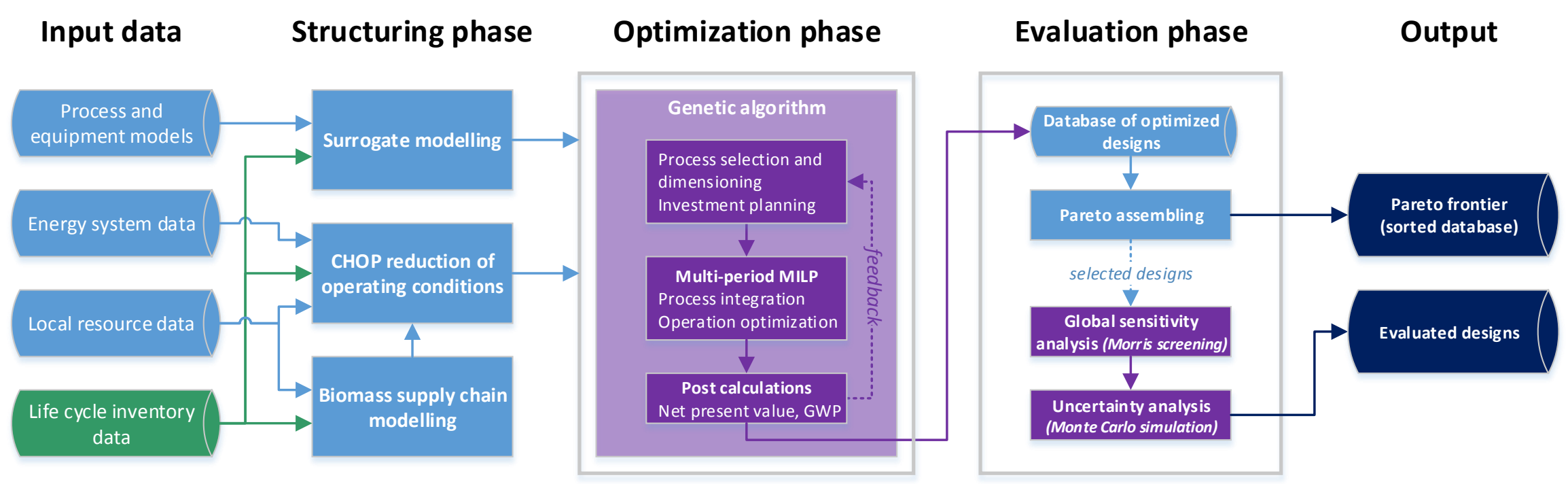

Figure 3: Design methodology structure. 
Figure 4

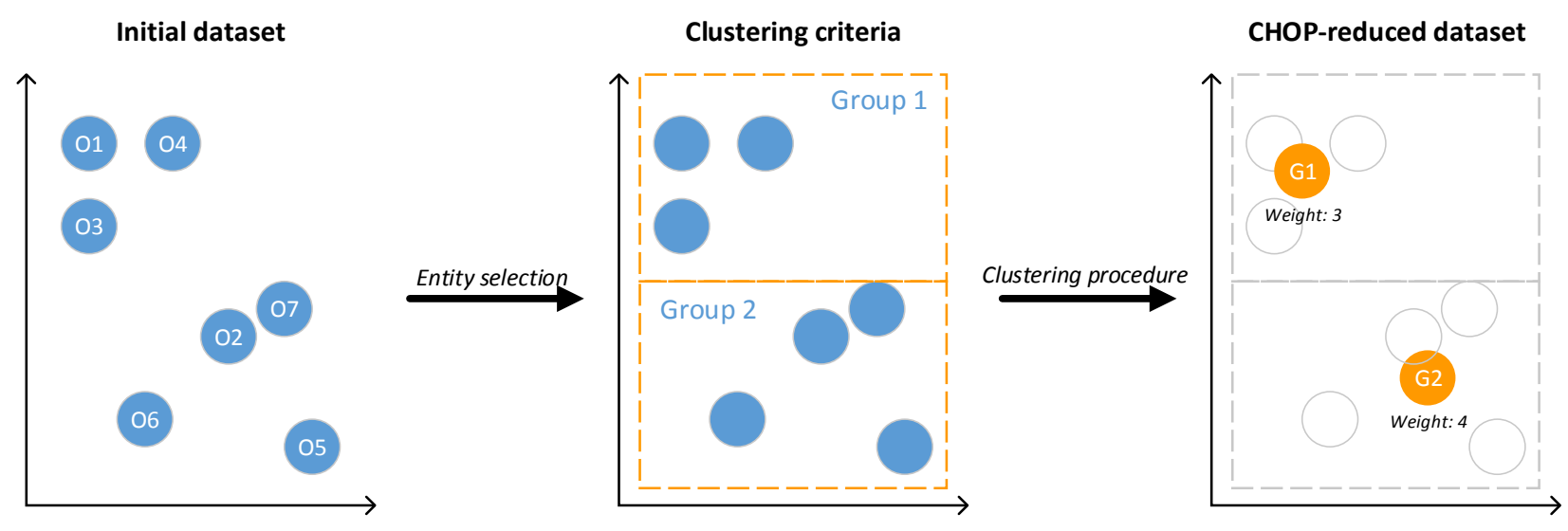

Figure 4: Principal sketch of the data aggregation principle applied in the CHOP method. Operating points $O_{j}$ are clustered and merged into $\mathrm{CHOP}$ groups $G_{i}$ with aggregated weight factors. Figure from [49]. 
Power price

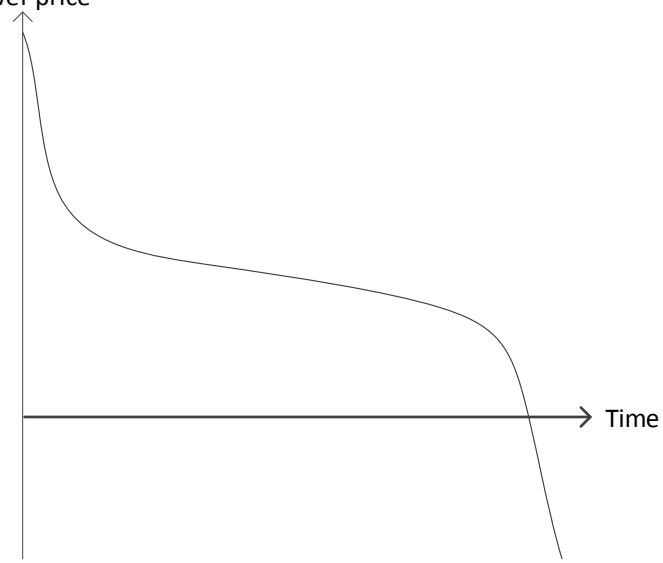

a) Power price

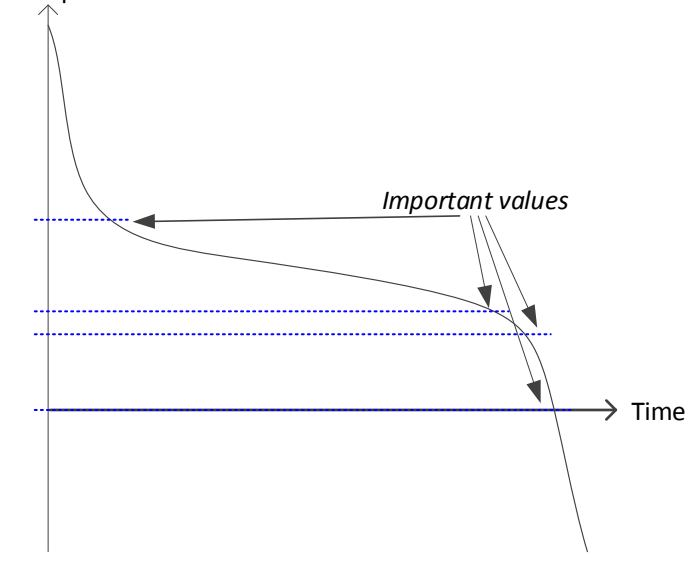

b) Power price

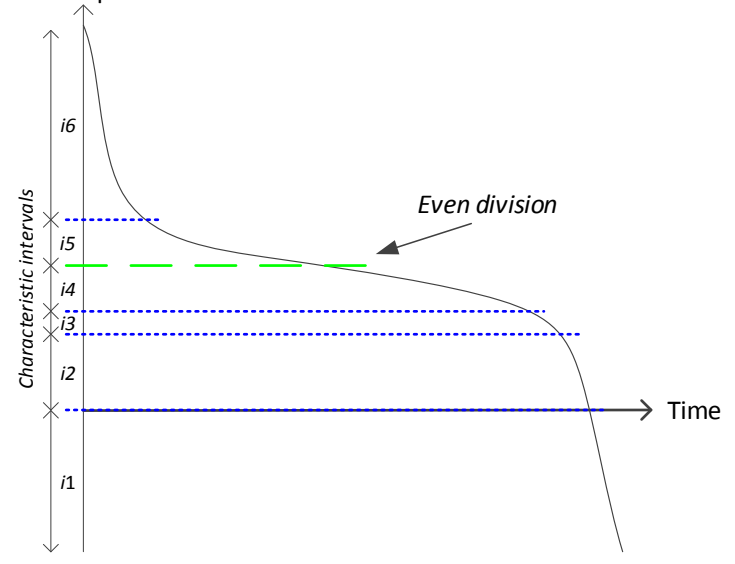

Figure 5: Illustrative example of the suggested two-step approach for defining characteristic intervals based on the cumulative parameter curve (left). Interval break points are set for a) Important values, and b) Even division. The characteristic intervals are indicated on the second axis in b). Figure from [49]. 


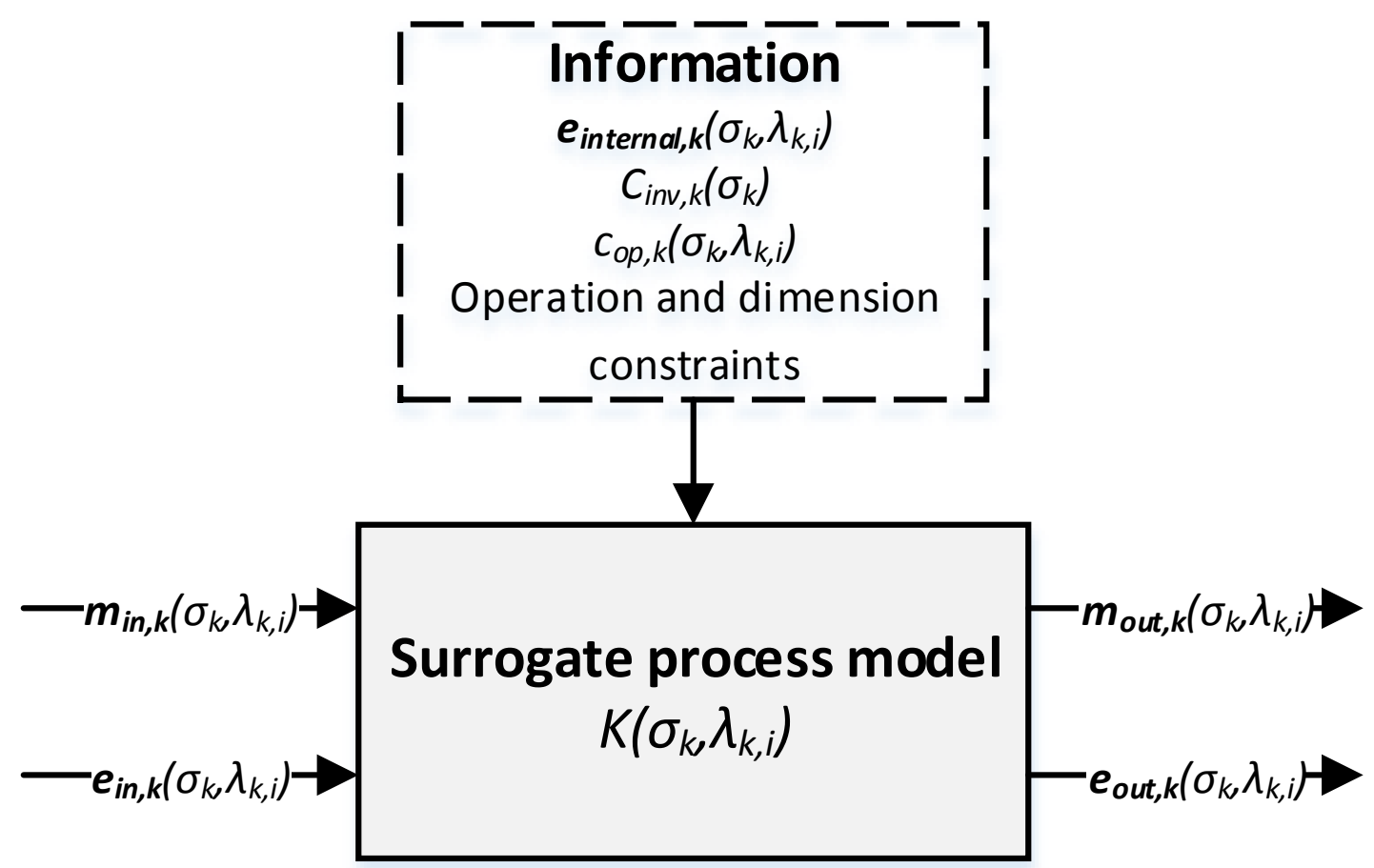

Figure 6: Generic illustration of a surrogate process model. 

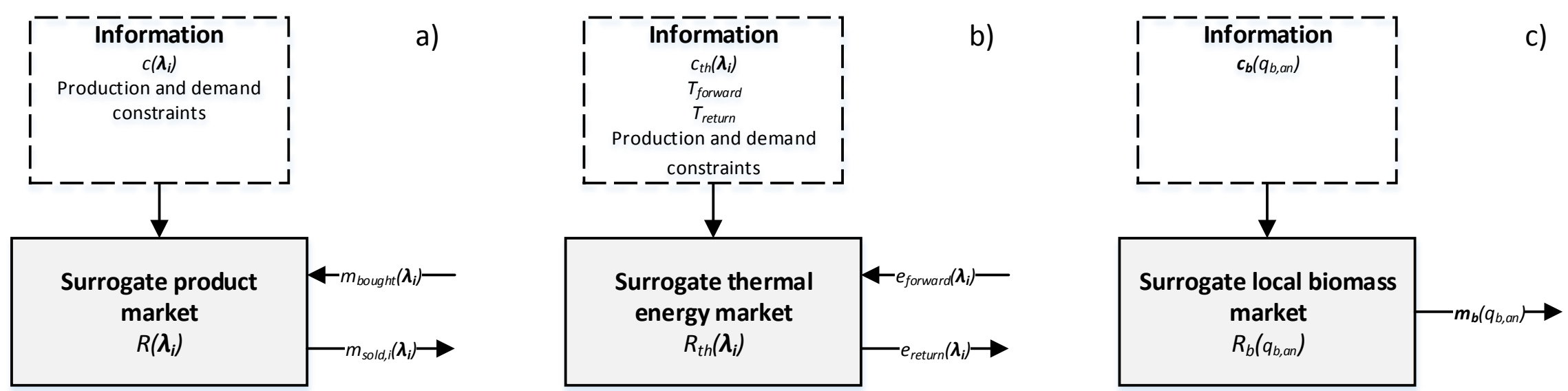

Figure 7: Generic illustration of a) a surrogate product or service market, b) a surrogate thermal energy market, and c) a surrogate local biomass market. 


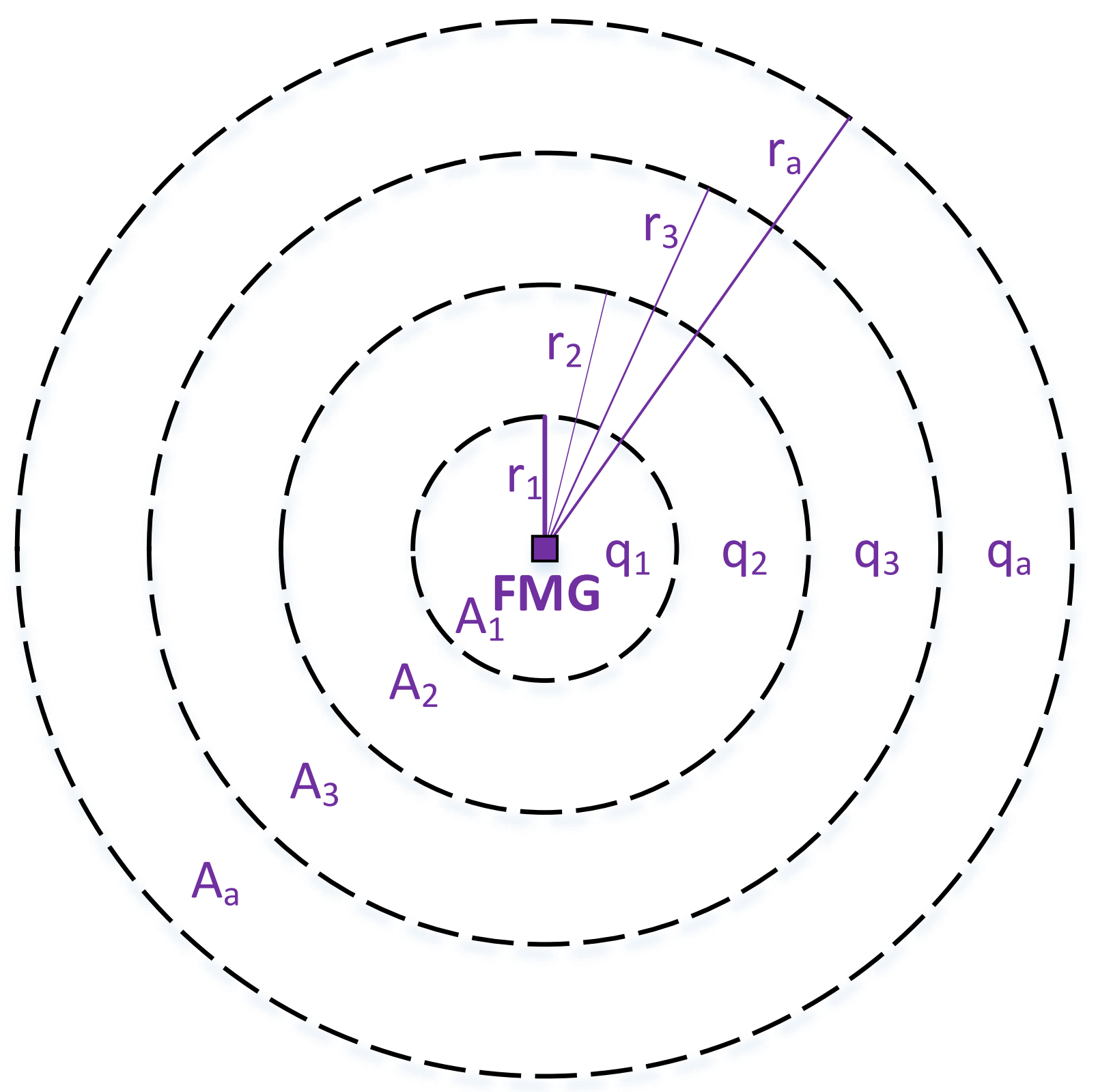

Figure 8: Applied land division around the FMG, with each circular area $\boldsymbol{A}_{\boldsymbol{a}}$ being represented by an annual biomass production quantity $\boldsymbol{q}_{\boldsymbol{a}}$, a minimum transportation distance $\boldsymbol{r}_{\boldsymbol{a}-\mathbf{1}}$ and a maximum transportation distance $\boldsymbol{r}_{\boldsymbol{a}}$. The number of circular areas $\boldsymbol{A}_{\boldsymbol{a}}$ is defined by the user. 


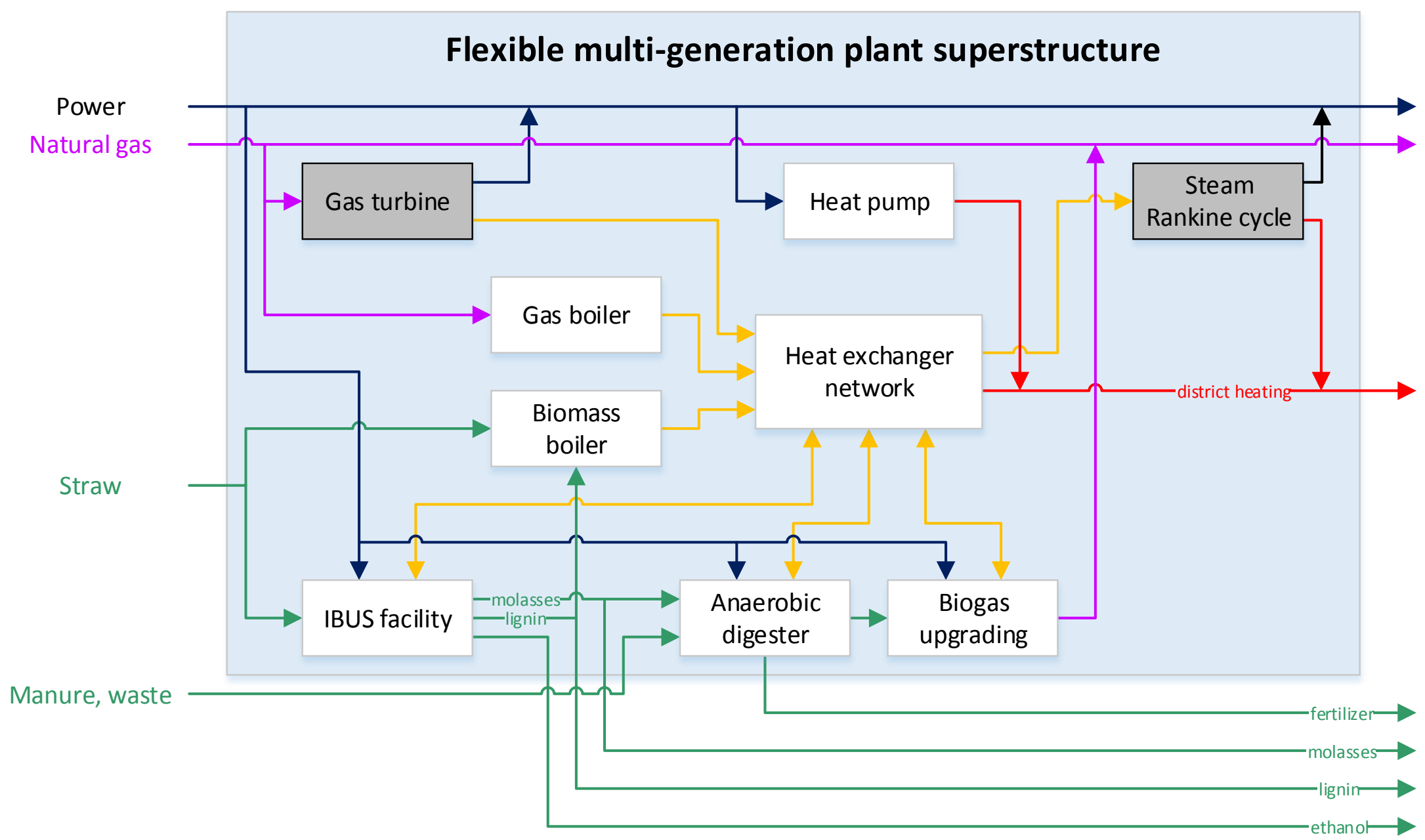

Figure 9: Superstructure of considered retrofit options for the existing combined cycle CHP. The gas turbine and steam Rankine cycle are grey as they are already installed. 




Figure 10: Scatter plot of reference operating points and CHOP groups with respect to power price and relative heat demand. 


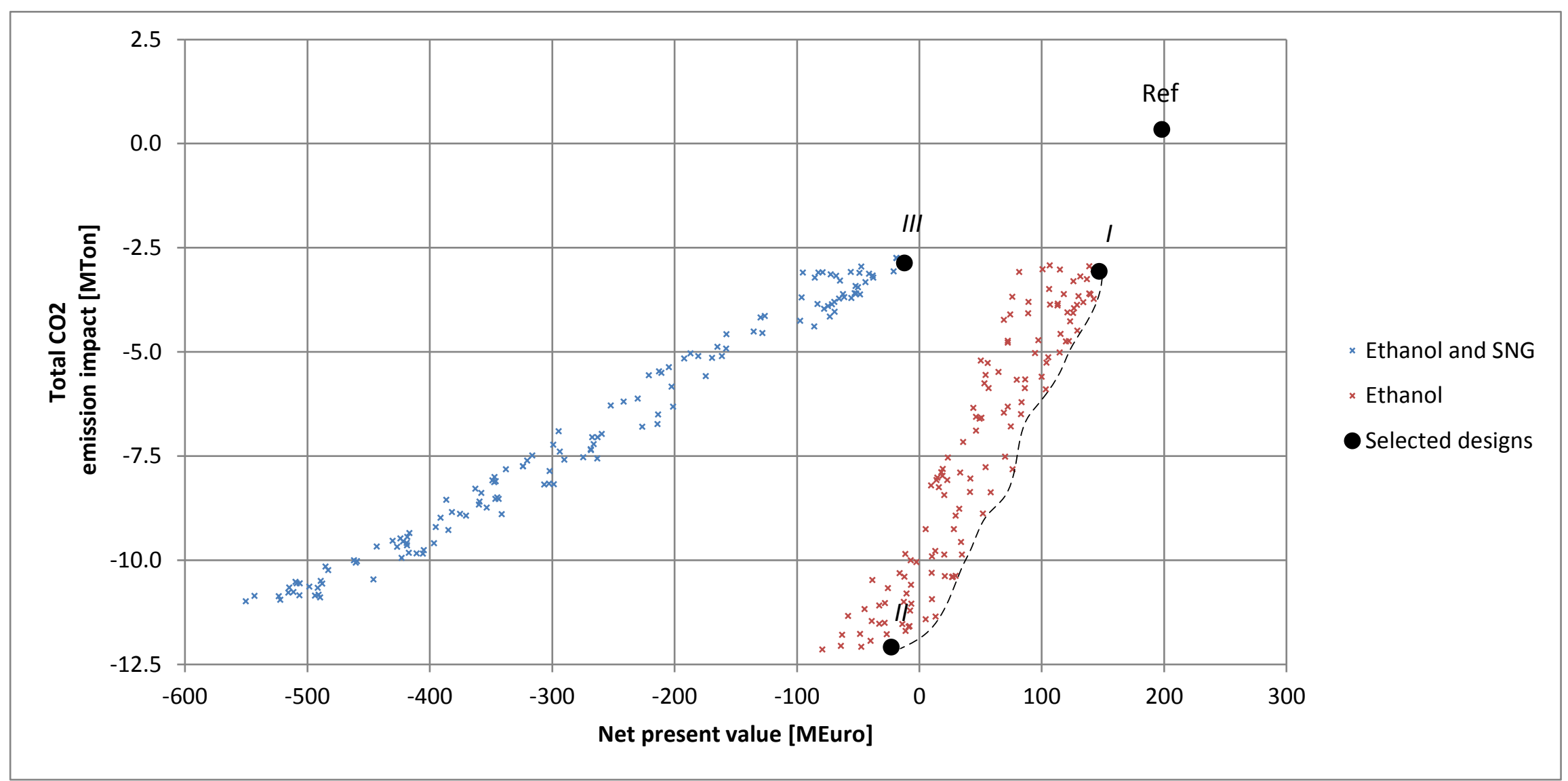

Figure 11: Scatter plot of optimized design solutions with respect to NPV and $\mathrm{CO}_{2}$ emission impact. The designs are clustered according to type of biomass treatment installed. The dotted line crudely illustrates the identified Pareto curve. The designs marked ' $l$ ', ' $I$ ' and ' $I I I^{\prime}$ are selected for further investigation. 'Ref' is the evaluated performance of the reference combined cycle CHP. 


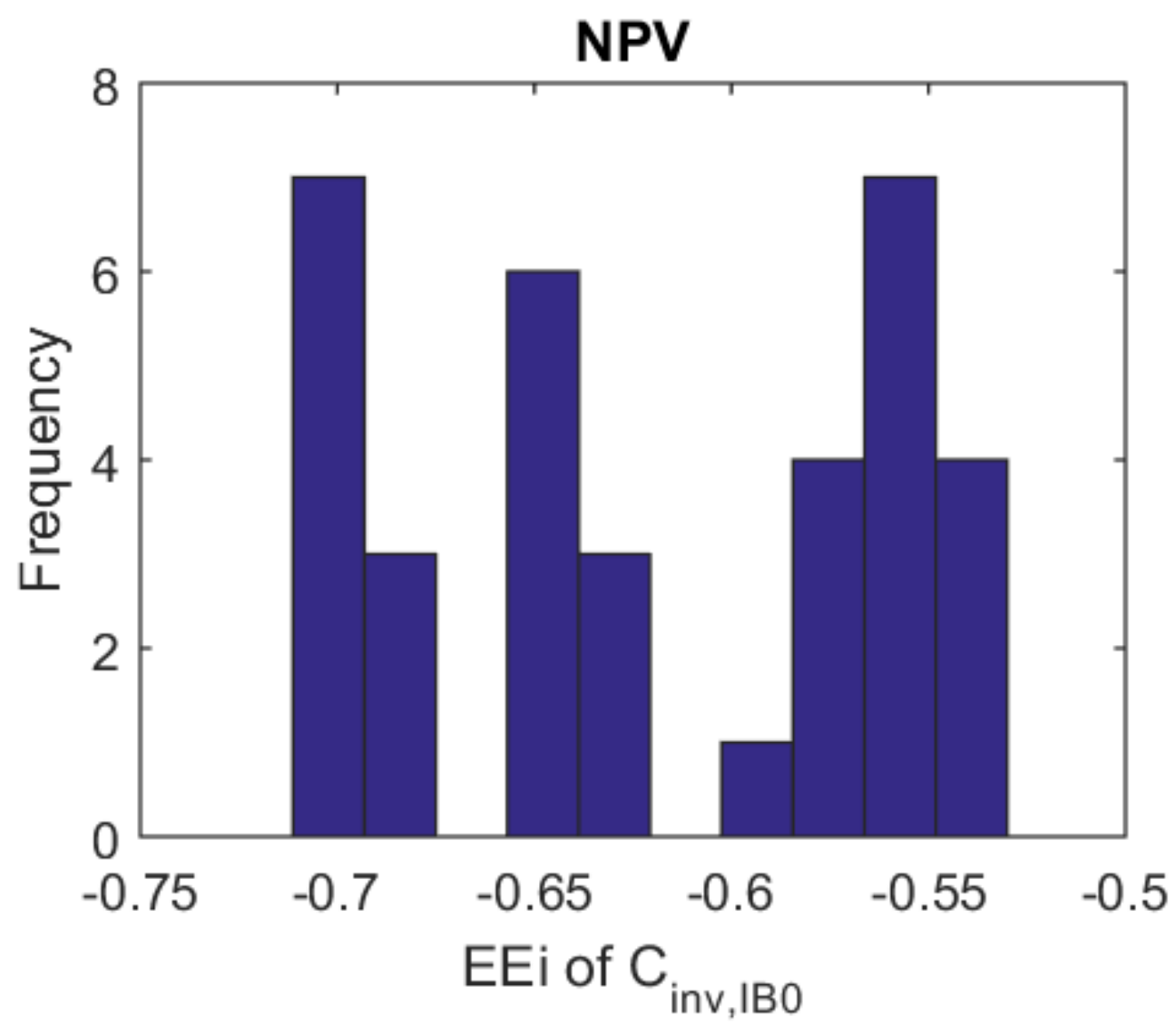

Figure 12: Histogram - elementary effect on NPV from reference ethanol facility Investment cost for design I. 

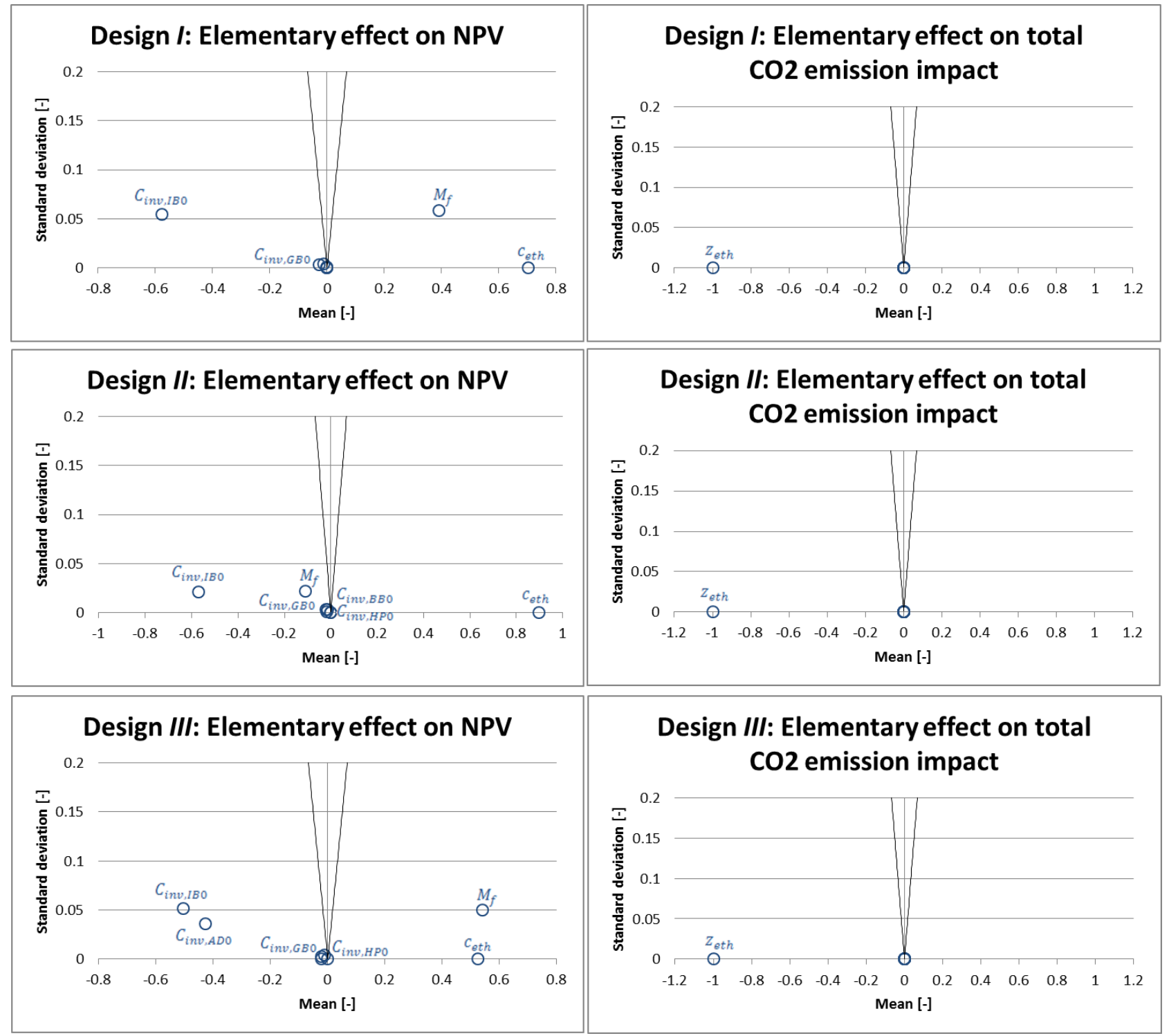

Figure 13: Means and standard deviations of sigma-scaled elementary effects on NPV (left) and total CO2 emission impact (right) from uncertain input parameters for designs I (top), II (middle), and III (bottom). 


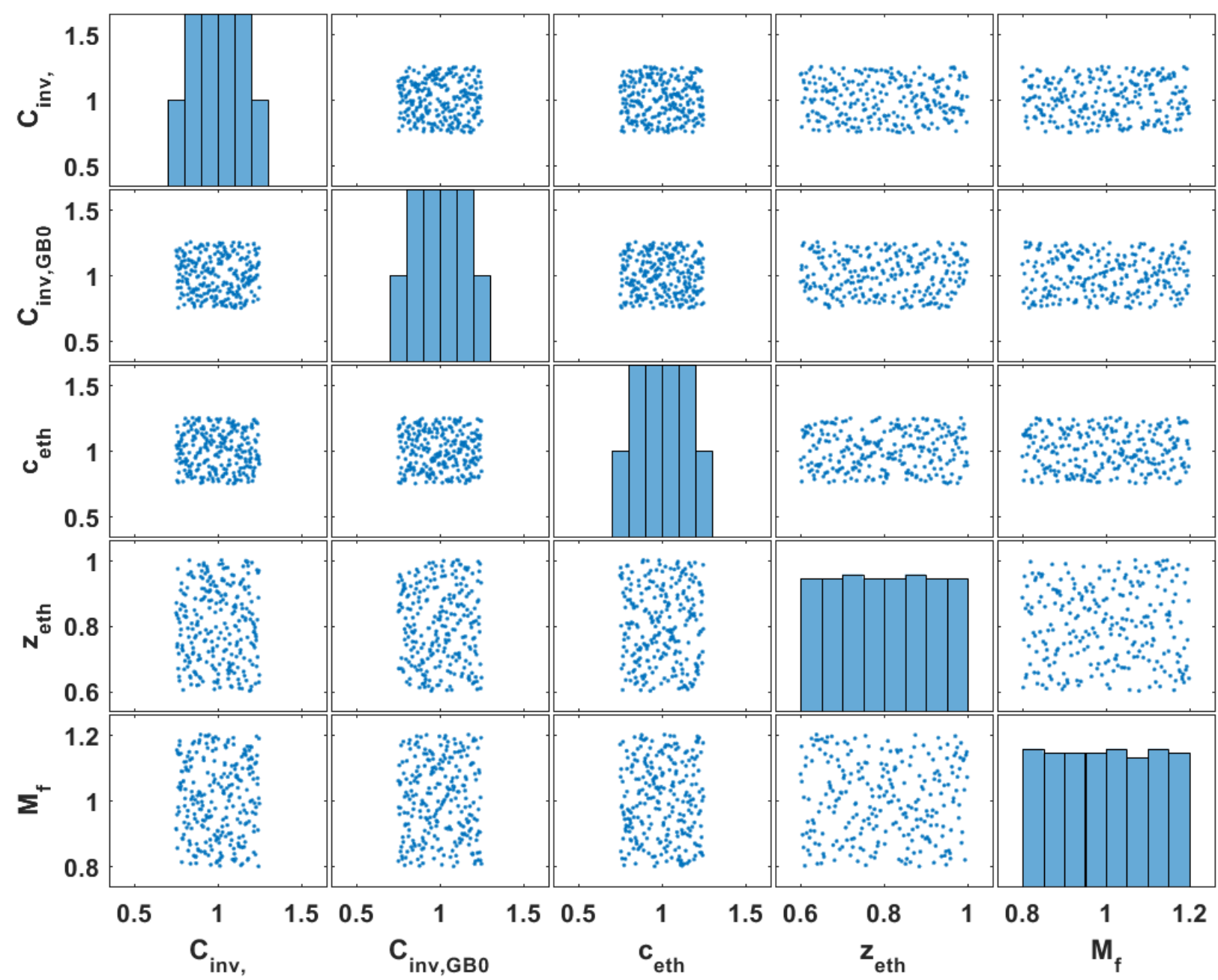

Figure 14: Example of Latin Hypercube Sampling - sample used for Monte Carlo simulations for design I. 


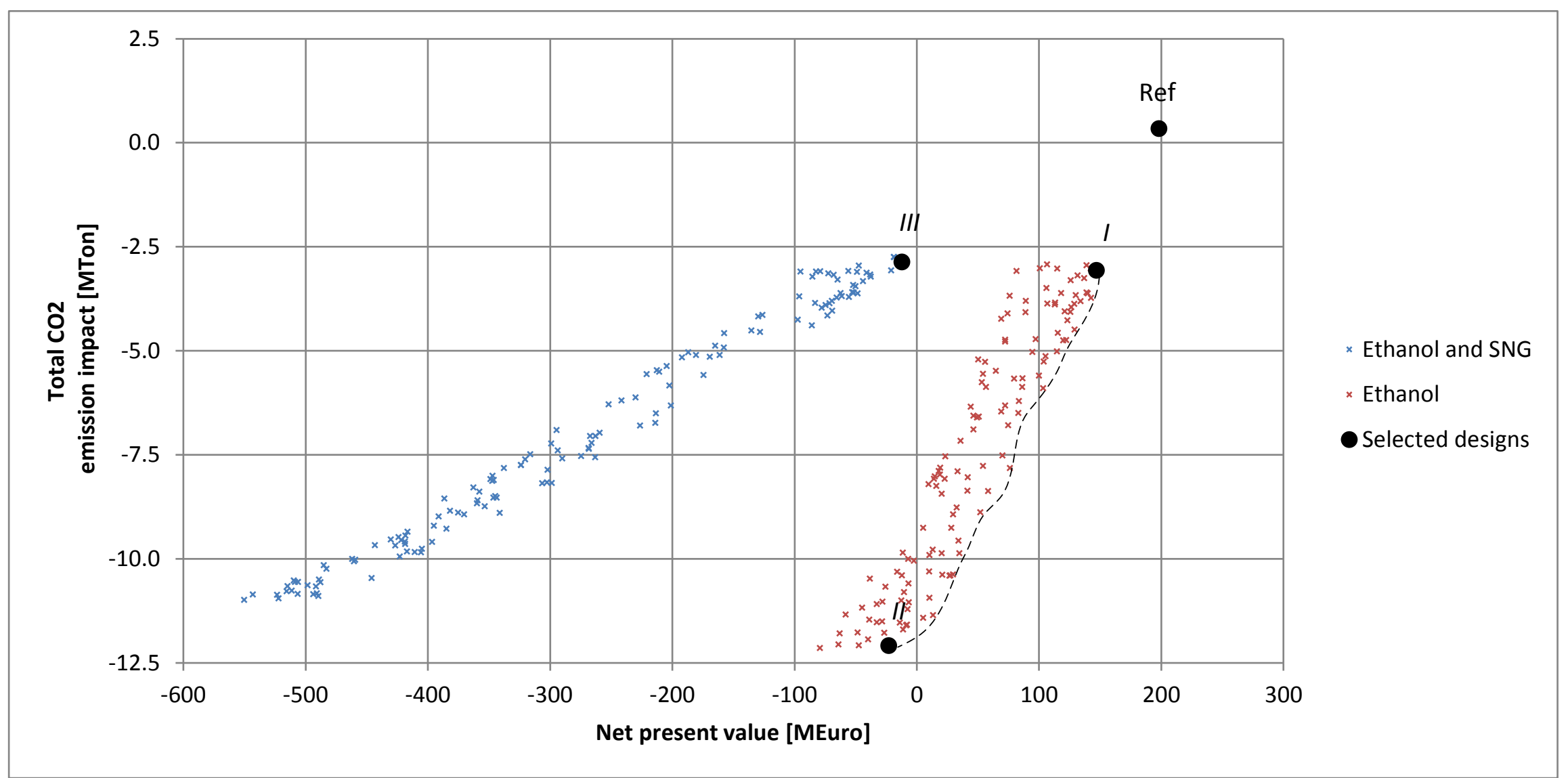

Figure 15: Scatter plot of optimized design solutions with respect to NPV and $\mathrm{CO}_{2}$-emission impact, with performance variability indicated for each of the three selected designs. NPV performance intervals represent $10^{\text {th }}$ to $90^{\text {th }}$ percentiles of predicted performance, while $\mathrm{CO}_{2}$ emission impact intervals represent $0^{\text {th }}$ to $90^{\text {th }}$ percentiles of predicted performance. 


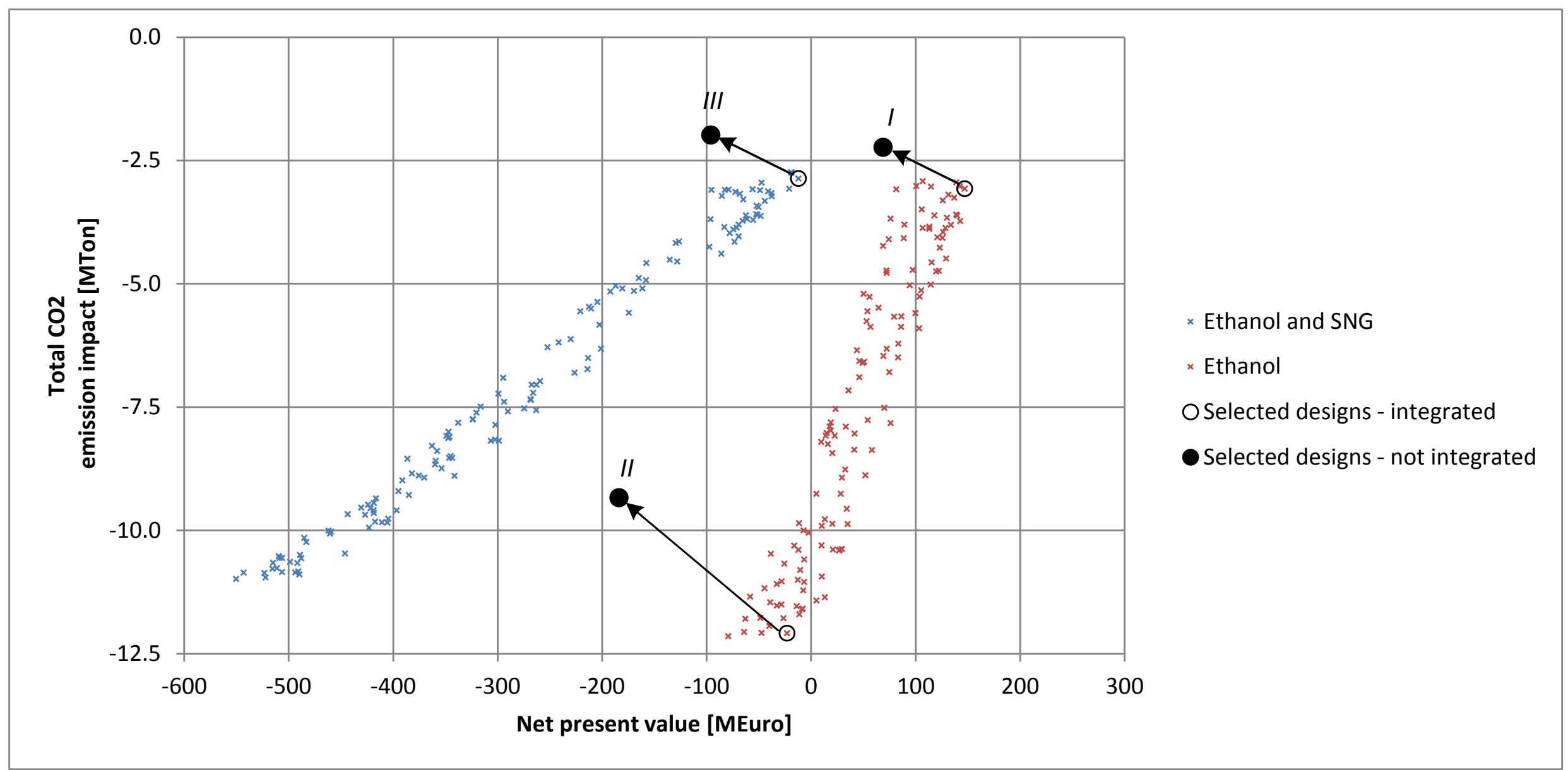

Figure 16: Performance of selected designs if systematic process integration had not been considered. 
Table 1: Data used for developing gas turbine and bottoming steam Rankine cycle surrogate models

\begin{tabular}{lclll}
\hline Facility & Variable & Description & Value & Reference \\
\hline Gas turbine (GT) & $P_{G T 100}$ & Nominal power capacity & $85 \mathrm{MW}$ & {$[63]$} \\
& $\dot{m}_{G T, \text { gas } 100}$ & Nominal gas consumption & $216.25 \mathrm{MW}$ & {$[63]^{\mathrm{a}}$} \\
& $\dot{e}_{G T, \text { off } 100}$ & Nominal off-gas heat flow & $105.3 \mathrm{MJ} / \mathrm{s}$ & {$[63]^{\mathrm{a}}$} \\
& $T_{\text {off,in }}$ & Off-gas temperature, before heat exchange & $465^{\circ} \mathrm{C}$ & {$[63]$} \\
& $T_{\text {off,out }}$ & Off-gas temperature after heat exchange & $68^{\circ} \mathrm{C}$ & {$[63]$} \\
Rankine cycle (SR) & $P_{S R 100}$ & Nominal power capacity & $23.3 \mathrm{MW}$ & {$[63]^{\mathrm{a}}$} \\
& $Q_{S R 100}$ & Nominal district heating generation & $82.0 \mathrm{MJ} / \mathrm{s}$ & {$[63]^{\mathrm{a}}$} \\
& $P_{S R, \text { turbine, in }}$ & Turbine inlet pressure & $15.5 \mathrm{bar}$ & assumption \\
& $T_{S R, \text { turbine, } \text { in }}$ & Turbine inlet temperature & $450^{\circ} \mathrm{C}$ & assumption \\
\hline
\end{tabular}

${ }^{\mathrm{a}}$ : Calculated based on operation data from [63] 
Table 2: Economic data on surrogate models

\begin{tabular}{|c|c|c|c|}
\hline Model & $\begin{array}{c}\text { Reference } \\
\text { investment cost } \\
C_{i n v, k 0}\end{array}$ & $\begin{array}{c}\text { Reference operation and } \\
\text { maintenance costs } \\
c_{O \& M, k 0}\end{array}$ & $\begin{array}{c}\text { Reference } \\
\text { dimension } \\
\sigma_{k 0}\end{array}$ \\
\hline Gas turbine (GT) & - & 2.50 Euro/MWh power [66] & - \\
\hline Steam Rankine cycle (SR) & - & 2.50 Euro/MWh power [66] & - \\
\hline Ethanol facility (IB) & 256.0 MEuro [65] & 35.9 MEuro/year [65] & $13.9 \mathrm{~kg} / \mathrm{s}$ straw [65] \\
\hline Biomethane facility (AD) & 179.8 MEuro [65] & 44.2 MEuro/year [65] & $13.9 \mathrm{~kg} / \mathrm{s} \mathrm{straw}^{\mathrm{b}}[65]$ \\
\hline Gas boiler (GB) & 2.0 MEuro [66] & 0.41 Euro/MWh heat [66] & $20 \mathrm{MJ} / \mathrm{s}[66]$ \\
\hline Biomass boiler (BB) & 40 MEuro [66] & 4.0 Euro/MWh heat [66] & $50 \mathrm{MJ} / \mathrm{s}[66]$ \\
\hline District heating heat pump (HP) & 6.8 MEuro [66] & 0.50 Euro/MWh heat [66] & $10 \mathrm{MJ} / \mathrm{s}[66]$ \\
\hline
\end{tabular}


Table 3: Thermal energy flow functions

\begin{tabular}{|c|c|c|c|c|c|}
\hline Process & Flow-description & Notation & Type & $\begin{array}{c}\text { Function } \\
{[\mathrm{MJ} / \mathrm{s}]}\end{array}$ & $T_{\text {in }} / T_{\text {out }}$ \\
\hline Gas turbine (GT) & Off-gas heat flow & $\dot{e}_{G T, o f f}$ & Hot & $1.053 \cdot \lambda_{G T}$ & $465^{\circ} \mathrm{C} / 68^{\circ} \mathrm{C}$ \\
\hline \multirow{4}{*}{$\begin{array}{l}\text { Steam Rankine cycle } \\
\text { (SR) }\end{array}$} & Water heating & $\dot{e}_{S R, c 1}$ & Cold & $0.200 \cdot \lambda_{S R}$ & $120^{\circ} \mathrm{C} / 200^{\circ} \mathrm{C}$ \\
\hline & Water evaporation & $\dot{e}_{S R, c 2}$ & Cold & $0.653 \cdot \lambda_{S R}$ & $200^{\circ} \mathrm{C} / 200^{\circ} \mathrm{C}$ \\
\hline & Steam superheating & $\dot{e}_{S R, c 3}$ & Cold & $0.200 \cdot \lambda_{S R}$ & $200^{\circ} \mathrm{C} / 450^{\circ} \mathrm{C}$ \\
\hline & Condensation & $\dot{e}_{S R, h}$ & Hot & $0.820 \cdot \lambda_{S R}$ & $120^{\circ} \mathrm{C} / 120^{\circ} \mathrm{C}$ \\
\hline \multirow[t]{12}{*}{ Ethanol facility (IB) } & $\begin{array}{l}\text { Steam generator, water } \\
\text { heating }\end{array}$ & $\dot{e}_{I B, s g 1}$ & Cold & $1.501 \cdot \sigma_{I B}$ & $15^{\circ} \mathrm{C} / 192^{\circ} \mathrm{C}$ \\
\hline & Steam generator, evaporation & $\dot{e}_{I B, s g 2}$ & Cold & $3.945 \cdot \sigma_{I B}$ & $192^{\circ} \mathrm{C} / 192^{\circ} \mathrm{C}$ \\
\hline & $\begin{array}{l}\text { Steam } \\
\text { superheating }\end{array}$ & $\dot{e}_{I B, s g 3}$ & Cold & $0.019 \cdot \sigma_{I B}$ & $192^{\circ} \mathrm{C} / 195^{\circ} \mathrm{C}$ \\
\hline & Pretreatment, cooling 1 & $\dot{e}_{I B, p r 1}$ & Hot & $0.341 \cdot \sigma_{I B}$ & $190^{\circ} \mathrm{C} / 100^{\circ} \mathrm{C}$ \\
\hline & Pretreatment, cooling 2 & $\dot{e}_{I B, p r 2}$ & Hot & $4.287 \cdot \sigma_{I B}$ & $100^{\circ} \mathrm{C} / 100^{\circ} \mathrm{C}$ \\
\hline & Pretreatment, cooling 3 & $\dot{e}_{I B, p r 3}$ & Hot & $0.092 \cdot \sigma_{I B}$ & $100^{\circ} \mathrm{C} / 80^{\circ} \mathrm{C}$ \\
\hline & Pretreatment, cooling 4 & $\dot{e}_{I B, p r 4}$ & Hot & $0.247 \cdot \sigma_{I B}$ & $100^{\circ} \mathrm{C} / 50^{\circ} \mathrm{C}$ \\
\hline & Liquefaction cooling & $\dot{e}_{I B, l q}$ & Hot & $0.060 \cdot \sigma_{I B}$ & $50^{\circ} \mathrm{C} / 33^{\circ} \mathrm{C}$ \\
\hline & Distillation, heating 1 & $\dot{e}_{I B, d s h 1}$ & Cold & $1.631 \cdot \sigma_{I B}$ & $100^{\circ} \mathrm{C} / 100^{\circ} \mathrm{C}$ \\
\hline & Distillation, heating 2 & $\dot{e}_{I B, d s h 2}$ & Cold & $0.021 \cdot \sigma_{I B}$ & $33^{\circ} \mathrm{C} / 37^{\circ} \mathrm{C}$ \\
\hline & Distillation, cooling 1 & $\dot{e}_{I B, d s c 1}$ & Cold & $1.044 \cdot \sigma_{I B}$ & $68^{\circ} \mathrm{C} / 68^{\circ} \mathrm{C}$ \\
\hline & Distillation, cooling 2 & $\dot{e}_{I B, d s c 2}$ & Cold & $0.807 \cdot \sigma_{I B}$ & $100^{\circ} \mathrm{C} / 30^{\circ} \mathrm{C}$ \\
\hline \multirow[t]{2}{*}{$\begin{array}{l}\text { Biomethane facility } \\
\text { (AD) }\end{array}$} & Anaerobic digester, heating & $\dot{e}_{A D, h}$ & Cold & $\begin{array}{l}0.249 \\
\cdot \omega_{A D} \sigma_{I B}\end{array}$ & $55^{\circ} \mathrm{C} / 55^{\circ} \mathrm{C}$ \\
\hline & Gas upgrading heat loss & $\dot{e}_{A D, l}$ & Hot & $\begin{array}{l}0.767 \\
\cdot \omega_{A D} \sigma_{I B}\end{array}$ & $100^{\circ} \mathrm{C} / 30^{\circ} \mathrm{C}$ \\
\hline Gas boiler (GB) & Gas boiler off-gas & $\dot{e}_{G B}$ & Hot & $\lambda_{G B} \sigma_{G B}$ & $465^{\circ} \mathrm{C} / 68^{\circ} \mathrm{C}$ \\
\hline Biomass boiler (BB) & Biomass boiler off-gas & $\dot{e}_{G B}$ & Hot & $\lambda_{B B} \sigma_{B B}$ & $465^{\circ} \mathrm{C} / 68^{\circ} \mathrm{C}$ \\
\hline $\begin{array}{l}\text { District heating heat } \\
\text { pump (HP) }\end{array}$ & Heat pump heat delivery & $\dot{e}_{H P}$ & Hot & $\lambda_{H P} \sigma_{H P}$ & $90^{\circ} \mathrm{C} / 90^{\circ} \mathrm{C}$ \\
\hline $\begin{array}{l}\text { District heating } \\
\text { demand (DH) }\end{array}$ & Heating of return flow & $\dot{e}_{D H}$ & Cold & $\lambda_{D H}$ & $40^{\circ} \mathrm{C} / 80^{\circ} \mathrm{C}$ \\
\hline
\end{tabular}


Table 4: Power flow functions

\begin{tabular}{llcc}
\hline \multicolumn{1}{c}{ Process } & \multicolumn{1}{c}{ Flow-description } & Notation & Function [MW] \\
\hline Gas turbine (GT) & GT power generation & $\dot{m}_{G T, e l}$ & $0.85 \cdot \lambda_{G T}$ \\
Steam Rankine cycle (SR) & SR power generation & $\dot{m}_{S R, e l}$ & $0.233 \cdot \lambda_{S R}$ \\
Ethanol facility (IB) & IB power consumption & $\dot{m}_{I B, e l}$ & $-0.583 \cdot \sigma_{I B}$ \\
Combined biogas facility (AD) & AD power consumption & $\dot{m}_{A D, e l}$ & $-2.048 \cdot \omega_{A D} \sigma_{I B}$ \\
District heating heat pump (HP) & HP power consumption & $\dot{m}_{H P, e l}$ & $-0.357 \cdot \sigma_{H P}$ \\
Power market & Power market exchange & $\dot{m}_{R, e l}$ & \\
\hline
\end{tabular}


Table 5

Table 5: Straw flow functions

\begin{tabular}{lccc}
\hline \multicolumn{1}{c}{ Process } & Flow-description & Notation & Function [MJ/s] \\
\hline Ethanol facility (IB) & Ethanol straw consumption & $\dot{m}_{I B, s t r a w}$ & $-15.1 \cdot \sigma_{I B}$ \\
Biomass boiler (BB) & Biomass boiler straw consumption & $\dot{m}_{B B, s t r a w}$ & $-1.031 \cdot \sigma_{I B}$ \\
Straw market & Straw import & $\dot{m}_{R, \text { el }}$ & \\
\hline
\end{tabular}


Table 6

Table 6: Solid biofuel flow functions

\begin{tabular}{lccc}
\hline \multicolumn{1}{c}{ Process } & Flow-description & Notation & Function [MJ/s] \\
\hline Ethanol facility (IB) & Ethanol solid biofuel production & $\dot{m}_{I B, \text { biofuel }}$ & $7.1 \cdot \sigma_{I B}$ \\
Biomass boiler (BB) & Biomass boiler biofuel consumption & $\dot{m}_{B B, \text { biofuel }}$ & $-1.031 \cdot \sigma_{B B} \lambda_{B B, \text { biofuel }}$ \\
Solid biofuel market & Solid biofuel export & $\dot{m}_{R, \text { biofuel }}$ & \\
\hline
\end{tabular}


Table 7

Table 7: $\mathrm{C} 5$ residues flow functions

\begin{tabular}{lccc}
\hline \multicolumn{1}{c}{ Process } & Flow-description & Notation & Function [MJ/s] \\
\hline Ethanol facility (IB) & Ethanol molasses production & $\dot{m}_{I B, m o l}$ & $3.9 \cdot \sigma_{I B}$ \\
Combined biogas facility (AD) & Anaerobic digester molasses consumption & $\dot{m}_{A D, m o l}$ & $-3.9 \cdot \omega_{A D} \sigma_{I B}$ \\
C5 residues market & C5 residues export & $\dot{m}_{R, m o l}$ & \\
\hline
\end{tabular}


Table 8: Natural gas flow functions

\begin{tabular}{lccc}
\hline \multicolumn{1}{c}{ Process } & Flow-description & Notation & Function [MJ/s] \\
\hline Gas turbine (GT) & Gas turbine gas consumption & $\dot{m}_{G T, \text { gas }}$ & $-2.165 \cdot \lambda_{G T}$ \\
\hline Combined biogas facility (AD) & Upgraded biogas production & $\dot{m}_{A D, \text { gas }}$ & $3.108 \cdot \omega_{A D} \sigma_{I B}$ \\
\hline Gas boiler (GB) & Gas boiler consumption & $\dot{m}_{G B, \text { gas }}$ & $-1.031 \cdot \sigma_{G B} \lambda_{G B}$ \\
\hline Natural gas market & Natural gas market exchange & $\dot{m}_{R, \text { gas }}$ & \\
\hline
\end{tabular}


Table 9

Table 9: Interval break points in the CHOP-reduced dataset.

\begin{tabular}{lccccccc}
\hline Interval break point & $\mathbf{1}$ & $\mathbf{2}$ & $\mathbf{3}$ & $\mathbf{4}$ & $\mathbf{5}$ & $\mathbf{6}$ & $\mathbf{7}$ \\
\hline Power price [Euro/MWh] & 0.00 & 25.00 & 33.00 & 41.00 & 49.00 & 57.00 & 65.00 \\
Relative heat demand [-] & 0.125 & 0.25 & 0.45 & 0.65 & 0.80 & 0.95 & - \\
\hline
\end{tabular}


Table 10: Duration of the defined CHOP groups in hours. Note that the duration is multiplied by six to represent the 30 -year lifetime of the facility rather than the 5 -year period that the historical values are taken from.

\begin{tabular}{lcccccccc}
\hline $\begin{array}{c}\text { CHOP group duration [h] } \\
\text { Heat interval \power interval }\end{array}$ & $\mathbf{1}$ & $\mathbf{2}$ & $\mathbf{3}$ & $\mathbf{4}$ & $\mathbf{5}$ & $\mathbf{6}$ & $\mathbf{7}$ & $\mathbf{8}$ \\
\hline $\mathbf{1}$ & 0 & 1,926 & 2,136 & 1,836 & 1,452 & 330 & 60 & 0 \\
$\mathbf{2}$ & 66 & 7,068 & 13,188 & 12,666 & 11,232 & 5,880 & 1,170 & 330 \\
$\mathbf{3}$ & 54 & 3,690 & 8,298 & 10,038 & 8,400 & 6,900 & 2,442 & 1,068 \\
$\mathbf{4}$ & 132 & 4,302 & 8,412 & 9,600 & 8,898 & 6,510 & 3,108 & 1,188 \\
$\mathbf{5}$ & 432 & 5,682 & 10,944 & 12,978 & 9,390 & 6,834 & 3,462 & 1,638 \\
$\mathbf{6}$ & 180 & 3,492 & 11,718 & 15,846 & 10,656 & 7,806 & 5,388 & 5,418 \\
$\mathbf{7}$ & 0 & 276 & 1,134 & 2,190 & 1,602 & 1,170 & 1,062 & 1,266 \\
\hline
\end{tabular}




\begin{tabular}{lccccccccc}
\hline $\begin{array}{c}\text { Relative heat demand [-] } \\
\text { Heat interval \power interval }\end{array}$ & $\mathbf{1}$ & $\mathbf{2}$ & $\mathbf{3}$ & $\mathbf{4}$ & $\mathbf{5}$ & $\mathbf{6}$ & $\mathbf{7}$ & $\mathbf{8}$ \\
\hline $\mathbf{1}$ & - & 0.105 & 0.106 & 0.105 & 0.105 & 0.107 & 0.109 & - \\
$\mathbf{2}$ & 0.204 & 0.178 & 0.180 & 0.182 & 0.186 & 0.191 & 0.199 & 0.210 \\
$\mathbf{3}$ & 0.392 & 0.334 & 0.335 & 0.334 & 0.334 & 0.344 & 0.348 & 0.339 \\
$\mathbf{4}$ & 0.563 & 0.553 & 0.546 & 0.550 & 0.547 & 0.544 & 0.549 & 0.547 \\
$\mathbf{5}$ & 0.731 & 0.721 & 0.727 & 0.726 & 0.721 & 0.720 & 0.721 & 0.740 \\
$\mathbf{6}$ & 0.848 & 0.858 & 0.866 & 0.870 & 0.872 & 0.871 & 0.876 & 0.878 \\
$\mathbf{7}$ & - & 0.961 & 0.961 & 0.960 & 0.962 & 0.961 & 0.963 & 0.963 \\
\hline
\end{tabular}


Table 12: Power price of the defined CHOP groups

\begin{tabular}{lcccccccc}
\hline $\begin{array}{c}\text { Power price [€/MWh] } \\
\text { Heat interval } \backslash \text { power interval }\end{array}$ & $\mathbf{1}$ & $\mathbf{2}$ & $\mathbf{3}$ & $\mathbf{4}$ & $\mathbf{5}$ & $\mathbf{6}$ & $\mathbf{7}$ & $\mathbf{8}$ \\
\hline $\mathbf{1}$ & - & 13.91 & 29.32 & 37.20 & 44.49 & 51.62 & 61.11 & - \\
$\mathbf{2}$ & -3.92 & 16.86 & 29.73 & 36.73 & 45.20 & 52.51 & 60.05 & 69.02 \\
$\mathbf{3}$ & -19.24 & 17.43 & 29.80 & 36.80 & 45.40 & 52.64 & 60.23 & 70.32 \\
$\mathbf{4}$ & -13.46 & 16.22 & 29.77 & 36.83 & 45.20 & 52.59 & 60.34 & 117.54 \\
$\mathbf{5}$ & -30.81 & 16.58 & 29.75 & 36.82 & 44.74 & 52.63 & 60.39 & 72.97 \\
$\mathbf{6}$ & -12.90 & 17.36 & 30.03 & 36.98 & 44.76 & 52.59 & 61.08 & 74.10 \\
$\mathbf{7}$ & - & 17.20 & 30.56 & 37.11 & 44.58 & 52.75 & 60.95 & 75.08 \\
\hline
\end{tabular}


Table 13: Economic data on, and $\mathrm{CO}_{2}$ emission impacts of, consumed and sold products

\begin{tabular}{|c|c|c|c|}
\hline \multirow[t]{2}{*}{ Products } & \multirow[t]{2}{*}{ Price [Euro/GJ] } & \multicolumn{2}{|c|}{ CO2 standard emission factor $[\mathrm{kg} / \mathrm{GJ}]$} \\
\hline & & Consumed & Sold \\
\hline Straw & $5.70[68]$ & 0.00 & - \\
\hline Natural gas & $6.24[68]$ & 56.1 & $-56.1^{c}[69]$ \\
\hline District heating & $12.08^{\mathrm{d}}[70]$ & - & $-33.0^{e}[71]$ \\
\hline Molasses (C5 residues) & $5.38[72]$ & - & $0.00^{f}[69]$ \\
\hline Solid biofuel (lignin) & $8.71[68]$ & 0.00 & $-101.1^{\mathrm{g}}[69]$ \\
\hline Ethanol & $16.05^{\mathrm{h}}[68]$ & - & $-69.2^{h}[69]$ \\
\hline Power & [defined in CHOP] & $0.413 / 0^{i}[71]$ & $-0.413 / 0^{i}[71]$ \\
\hline
\end{tabular}

c: Sold natural gas (bio-methane) is assumed to replace natural gas in the grid.

${ }^{\mathrm{d}}$ : Reference heat-to-grid selling price in $\mathbf{2 0 2 0}$ for natural gas-based combined cycle power plants in western Denmark.

e: Average $\mathrm{CO} 2$ emission for district heating in Denmark.

f: For simplicity, no avoided $\mathrm{CO}_{2}$ emission is associated with sold molasses. In reality, molasses may be sold as animal feed, thereby potentially replacing imported soy beans or similar, thus reducing $\mathrm{CO}_{2}$ emissions.

$\mathrm{g}$ : The solid biofuel, from which most of the alkaline metals have been removed, is assumed to replace coal.

${ }^{\mathrm{h}}$ : Ethanol is assumed to be sold as, and replace, gasoline.

: Marginal power generation $\mathrm{CO}_{2}$ emission is set equal to the average $\mathrm{CO}_{2}$ emission from power generation in Denmark, apart from periods with negative power prices where the marginal $\mathrm{CO}_{2}$ emission is set to zero to represent wind turbine power generation. 
Table 14: Biomass supply chain model

\begin{tabular}{cccccc}
\hline Area & Radius & $\begin{array}{c}\text { Annual yield } \\
\boldsymbol{q}_{\boldsymbol{b}, \boldsymbol{a n}} \text { [ton] }\end{array}$ & $\begin{array}{c}\text { Fixed logistics costs } \\
\boldsymbol{c}_{\boldsymbol{b}, \mathbf{0}} \text { [Euro/GJ] }\end{array}$ & $\begin{array}{c}\text { Transport costs } \\
\boldsymbol{c}_{\boldsymbol{b}, \boldsymbol{t r}} \text { [Euro/GJ] }\end{array}$ & $\begin{array}{c}\text { Marginal straw cost } \\
\boldsymbol{c}_{\boldsymbol{b}} \text { [Euro/GJ] }\end{array}$ \\
\hline $\boldsymbol{A}_{\mathbf{1}}$ & $10 \mathrm{~km}$ & 26,269 & 0.005 & 0 & 5.709 \\
$\boldsymbol{A}_{\mathbf{2}}$ & $30 \mathrm{~km}$ & 210,154 & 0.005 & 0.215 & 5.924 \\
$\boldsymbol{A}_{\mathbf{3}}$ & $50 \mathrm{~km}$ & 420,308 & 0.005 & 0.397 & 6.102 \\
\hline
\end{tabular}


Table 15: Design optimization variables and constraints

\begin{tabular}{clcc}
\hline Design variable & \multicolumn{1}{c}{ Description } & Lower bound & Upper bound \\
\hline $\boldsymbol{\sigma}_{\boldsymbol{I B}}$ & Ethanol facility dimension, in kg/s straw processed & $5 \mathrm{~kg} \mathrm{straw} / \mathrm{s}$ & $20 \mathrm{~kg} \mathrm{straw} / \mathrm{s}^{j}$ \\
$\boldsymbol{\omega}_{\boldsymbol{A} \boldsymbol{D}}$ & Installation of a combined biogas facility, decision & Integer decision $\{0,1\}$ \\
$\boldsymbol{\sigma}_{\boldsymbol{B} \boldsymbol{B}}$ & Biomass boiler dimension, in MJ/s heat delivered & $0 \mathrm{MJ} / \mathrm{s}$ & $100 \mathrm{MJ} / \mathrm{s}$ \\
$\boldsymbol{\sigma}_{\boldsymbol{H P}}$ & $\begin{array}{c}\text { District heating heat pump dimension, in } \mathrm{MJ} / \mathrm{s} \\
\text { heat delivered }\end{array}$ & $0 \mathrm{MJ} / \mathrm{s}$ & $50 \mathrm{MJ} / \mathrm{s}$ \\
& & & \\
\hline
\end{tabular}

${ }^{j}$ : Equal to the maximum annual production of straw within a $50 \mathrm{~km}$ radius of the plant under the assumptions in section 3.1.3. 
Table 16: Operation optimization variables and constraints

\begin{tabular}{cllc}
\hline $\begin{array}{c}\text { Operation } \\
\text { variable }\end{array}$ & \multicolumn{1}{c}{ Description } & Lower bound & Upper bound \\
\hline $\boldsymbol{\nu}_{\boldsymbol{G}}$ & Gas turbine operated & Integer decision $\{0,1\}$ \\
$\lambda_{\boldsymbol{G}}$ & Gas turbine load & 0.20 & 1.00 \\
$\boldsymbol{\nu}_{\boldsymbol{G} T}$ & Steam Rankine cycle operated & Integer decision $\{0,1\}$ \\
$\lambda_{\boldsymbol{S}}$ & Steam Rankine cycle load & 0.40 & 1.00 \\
$\lambda_{G \boldsymbol{B}}$ & Gas boiler load & 0.00 & 1.00 \\
$\lambda_{\boldsymbol{B} \boldsymbol{B}}$ & Biomass boiler load & 0.00 & 1.00 \\
$\lambda_{\boldsymbol{H P}}$ & Heat pump load & 0.00 & 1.00 \\
\hline
\end{tabular}


Table 17: Uncertain parameters and their distributions

\begin{tabular}{|c|c|c|c|c|c|}
\hline Parameter & Description & Distribution & Reference value & $\begin{array}{l}\text { Lower } \\
\text { bound }\end{array}$ & $\begin{array}{l}\text { Upper } \\
\text { bound }\end{array}$ \\
\hline$C_{\text {inv }, I B 0}$ & $\begin{array}{l}\text { Investment cost, reference } \\
\text { ethanol facility }\end{array}$ & Uniform & 256.0 MEuro & 192.0 MEuro & 320.0 MEuro \\
\hline$C_{i n v, A D 0}$ & $\begin{array}{l}\text { Investment cost, reference } \\
\text { combined biogas facility }\end{array}$ & Uniform & 199.8 MEuro & 149.9 MEuro & 249.8 MEuro \\
\hline$C_{i n v, G B 0}$ & $\begin{array}{l}\text { Investment cost, reference } \\
\text { gas boiler }\end{array}$ & Uniform & 2.0 MEuro & 1.5 MEuro & 2.5 MEuro \\
\hline$C_{i n v, B B 0}$ & $\begin{array}{l}\text { Investment cost, reference } \\
\text { biomass boiler }\end{array}$ & Uniform & 40.0 MEuro & 30.0 MEuro & 50.0 MEuro \\
\hline$C_{i n v, H P 0}$ & $\begin{array}{l}\text { Investment cost, reference } \\
\text { district heating heat pump }\end{array}$ & Uniform & 6.8 MEuro & 5.1 MEuro & 8.5 MEuro \\
\hline$c_{e t h}$ & Ethanol price & Uniform & 5.70 Euro/GJ & 4.28 Euro/GJ & 7.13 Euro/GJ \\
\hline$z_{\text {eth }}$ & $\begin{array}{l}\text { Ethanol displaced } \mathrm{CO}_{2} \\
\text { emission }\end{array}$ & Uniform & $-69.2 \mathrm{~kg} / \mathrm{GJ}$ & $-41.5 \mathrm{~kg} / \mathrm{GJ}$ & $-69.2 \mathrm{~kg} / \mathrm{GJ}$ \\
\hline$M_{f}$ & Investment scaling constant & Uniform & 0.75 & 0.6 & 0.9 \\
\hline
\end{tabular}


Table 18

Table 18: Characteristics of the selected designs

\begin{tabular}{lcccccccc}
\hline Design & $\begin{array}{c}\text { NPV } \\
{[\mathrm{MEuro}]}\end{array}$ & $\begin{array}{c}\mathrm{CO}_{2} \text {-emission } \\
\text { impact [MTon] }\end{array}$ & $\begin{array}{c}\boldsymbol{\sigma}_{\boldsymbol{I B}} \\
{[\mathrm{kg} / \mathrm{s}]}\end{array}$ & $\begin{array}{c}\boldsymbol{v}_{\boldsymbol{A D}} \\
{[-]}\end{array}$ & $\begin{array}{c}\boldsymbol{\sigma}_{G B} \\
{[\mathrm{MJ} / \mathrm{s}]}\end{array}$ & $\begin{array}{c}\boldsymbol{\sigma}_{\boldsymbol{B B}} \\
{[\mathrm{MJ} / \mathrm{s}]}\end{array}$ & $\begin{array}{c}\boldsymbol{\sigma}_{H P P} \\
{[\mathrm{MJ} / \mathrm{s}]}\end{array}$ & $\begin{array}{c}\boldsymbol{C}_{\boldsymbol{H E N}} \\
{[\mathrm{MEuro}]}\end{array}$ \\
\hline Ref & 198.2 & 0.34 & 0.0 & 0 & 0.0 & 0.0 & 0.0 & 0 \\
I & 147.0 & -3.07 & 5.2 & 0 & 80.1 & 1.1 & 0.3 & 4.83 \\
II & -22.9 & -12.09 & 19.6 & 0 & 143.8 & 11.1 & 19.8 & 7.51 \\
III & -12.1 & -2.87 & 5.3 & 1 & 70.0 & 1.3 & 9.0 & 4.98 \\
\hline
\end{tabular}


Table 19

Table 19: Uncertain input parameters considered in Monte Carlo simulations for each of the three selected designs

\begin{tabular}{|c|c|c|c|c|c|c|c|c|}
\hline Design & $C_{i n v, I B 0}$ & $C_{i n v, A D 0}$ & $C_{i n v, G B 0}$ & $C_{i n v, B B 0}$ & $C_{i n v, H P 0}$ & $c_{\text {eth }}$ & $Z_{\text {eth }}$ & $M_{f}$ \\
\hline$I$ & $x$ & & $x$ & & & $x$ & $x$ & $x$ \\
\hline II & $X$ & & $X$ & $X$ & $X$ & $X$ & $X$ & $X$ \\
\hline III & $X$ & $X$ & $X$ & & $x$ & $X$ & $X$ & $X$ \\
\hline
\end{tabular}

